\title{
Ductility Evaluation of Damaged Recycled Aggregate Concrete Columns Repaired With Carbon Fiber-Reinforced Polymer and Large Rupture Strain FRP
}

\author{
Pengda Li, Yao Zhao, Xu Long, Yingwu Zhou* and Zhenyuan Chen \\ Guangdong Provincial Key Laboratory of Durability for Marine Civil Engineering, Shenzhen University, Shenzhen, China
}

\section{OPEN ACCESS}

Edited by:

Xiangming Zhou,

Brunel University London, United Kingdom

Reviewed by:

Zehra Canan Girgin,

Ylldz Technical University, Turkey

Jian-Guo Dai,

Hong Kong Polytechnic University,

Hong Kong

João Nuno Pacheco,

Investigação e Inovação em

Engenharia Civil para a

Sustentabilidade (CERIS), Portugal

*Correspondence: Yingwu Zhou

ywzhou@szu.edu.cn

Specialty section: This article was submitted to

Structural Materials,

a section of the journal

Frontiers in Materials

Received: 31 May 2020 Accepted: 14 September 2020 Published: 23 November 2020

Citation:

Li P, Zhao Y, Long X, Zhou Y and Chen $Z$ (2020) Ductility Evaluation of

Damaged Recycled Aggregate

Concrete Columns Repaired With Carbon Fiber-Reinforced Polymer and

Large Rupture Strain FRP.

Front. Mater. 7:568036.

doi: 10.3389/fmats.2020.568036
The inherent defects of recycled aggregate concrete (RAC) include the complex interfacial transition zone (ITZ) and the many micro-cracks that appear during its producing process, which result in some inferior mechanical properties compared with natural aggregate concrete (NAC). This drawback usually prevents RAC from being selected for structural purposes. Existing research has shown that the strength and ductility of damaged concrete in compression members can be significantly enhanced through external confinement using fiber-reinforced polymer (FRP) wraps. This application has been widely used in concrete structural repair and retrofitting technology. However, research on the effects of RAC damage coupled with different load damage conditions is rare, as is information on the mechanical properties of RAC reinforced with FRP jackets. This paper presents the results of an experimental study on the behavior of pre-damaged recycled aggregate concrete cylinders that were repaired with carbon fiber-reinforced polymer (CFRP) or large rupture strain (LRS)-FRP jackets. Tests were conducted on 58 concrete cylinders with variations in the replacement ratio, damage levels, and FRP properties. Test results demonstrated that the ultimate strain and strength of damaged recycled aggregate concrete could be significantly enhanced by FRP jackets and that aggregate quality plays a vital role in the strength of confined concrete. Also, the energy absorption of CFRP- and LRS-FRP-confined RAC were evaluated. The analysis indicated that, compared with CFRP-confined RAC, LRS-FRP can greatly improve the energy absorption capacity of RAC; thus, LRS-FRP confined concrete has a good potential to achieve a ductile design for concrete columns, especially when used in seismic reinforcement.

Keywords: recycled aggregates, CFRP, LRS-FRP, ductility enhancement, energy absorption capacity

\section{INTRODUCTION}

With the acceleration of modern urbanization, the consumption of concrete made from natural resources (such as stone and sand) has grown rapidly. Among these resources, the coarse aggregates (crushed stones), which occupy about half of the total amount of concrete materials, could become depleted in some regions, such as coastal cities. Overexploitation and long-distance transportation of these raw materials inevitably harms the environment. (Poon et al., 2004; Xiao et al., 2005; Casuccio 
et al., 2008; Xiao et al., 2012; Zhang et al., 2019). Meanwhile, urbanization inevitably continues to generate large amounts of construction and demolition waste; moreover, the landfills or disposal sites set aside for this construction and demolition waste already present new challenges for overburdened urban landscapes. Too much construction waste and a shortage of raw resources are two major problems associated with the urbanization process. To solve these problems, more research on transforming construction waste into recycled aggregate (RA) is needed. Poon et al. (2004) recommended modifying the surface properties and pore structure of RA. Xiao et al. (2005) discussed some RA deficiencies but noted that they were still viable in some civil engineering practical applications. Barnhouse and Srubar (2016) recognized the pervious value of RA for pavement subject to flooding. Chen et al. (2019) investigated the mechanical fatigue properties of pervious concrete and developed an improved elasto-plastic and fracture (EPF) model to better define the relationship between RA plastic strain, unloading strain, and fracture parameters. The application of recycled aggregate concrete (RAC) can not only alleviate the pressure of the natural aggregate resource shortage but can also reduce the environmental degradation caused by construction and demolition waste (Behera et al., 2014). However, after decades of effort, scholars found that the source of recycled aggregates is very complex and may include various types of defects, such as cracking during the crushing process or old mortar attached to the aggregate surface (Silva et al., 2014). The complexity of defining aggregate sources makes specifications and standards impossible, which limits the widespread application of recycled aggregates. To accommodate for the dwindling of natural aggregates (NAs) in some areas, stable, high-quality aggregates must be found or created. Our previous study indicated that natural aggregates, including flaky and elongated particles, lead to higher voids than cubical, rounded, or well-graded particles (Li et al., 2019b). The aggregate shape factor plays a vital role in the design and performance of the concrete mix, and the compressive strength of concrete decreases with the increase of flaky and elongated aggregates. Therefore, using RAs and poor-quality aggregates can seriously reduce the strength of the concrete made from them (Xiao et al., 2005; Tabsh and Abdelfatah, 2009; Li et al., 2019b). One objective of this RA research is to increase acceptance of RA as a viable alternative to natural aggregates, which needs to be protected from an ecological viewpoint. This paper presents the possibility that RA could supplement concrete construction partially or even replace some forms of traditional RC completely.

In recent years, many scholars have conducted extensive research on the mechanical properties of RAC and elaborated on the performance of RAC based on the effects of different RA replacement ratios (defined as the ratio of the mass of RAs to the total mass of coarse aggregate (Zhao et al., 2015; Chen et al., 2016). Previous studies (Silva et al., 2014; Omary et al., 2016; Zhang et al., 2017) have found that the crushing index and water absorption of RAs are $60 \%$ and $700 \%$ larger than NAs, respectively. This is due to the many pores and cracks in RA, and the high porosity causes RAC's lower stiffness and higher shrinkage and creep than that of NAC. Moreover, it is also well known that RAC has three kinds of interfacial transition zones (ITZs): old stone and old mortar, old stone and new mortar, and old mortar and new mortar. These weak links in RAC also cause RAC to have poor mechanical properties (Poon et al., 2004; Etxeberria et al., 2007; Juan et al., 2009; Silva et al., 2014). To reduce the negative impact of the existing cement mortar surface layer on the mechanical properties of RAC, physical or chemical methods have been adopted by previous scholars to remove or strengthen the cement mortar layer on the RA surface (Juan et al., 2009; Xiao et al., 2012; Behera et al., 2014; Kou et al., 2014; Shi et al., 2016). However, these physical and chemical treatment methods are costly, and inevitably have some negative impact on the environment. Also, these obtained improvements in these surface treatment methods depend largely on the quality of concrete waste.

Due to the above disadvantages, the application of RAC is mainly limited to non-structural situations, such as pavements and backfill. However, new opportunities have surfaced for RAC based on the increasing acceptance of fiber-reinforced polymer (FRP) in engineering applications. FRP materials continue to grow in popularity based on their light weight, high strength, and corrosion resistance (De Lorenzis and Tepfers, 2003; Zeng et al., 2018; Li et al., 2019b; Wei et al., 2020). Zhou et al. (2016) proved FRP to be an effective reinforcement when used to jacket RAC compression members when the concrete core is in a triaxial compressive stress state through effective lateral confinement. This method can greatly increase the ultimate stress of concrete in confined systems and effectively make up for the internal defects of aggregates (Lam and Teng, 2003; Jiang and Wu, 2012; Nisticò and Monti, 2013; Song et al.,. 2013; Li et al., 2018a; Rousakis, 2018; Li et al., 2019a; Zhou et al., 2019).

Over the past two decades, many scholars have conducted valuable research on traditional FRP-confined NAC and RAC and discussed the effects of the parameters, such as the RA replacement ratio, confinement stiffness, load patterns, and cross-sectional factors. FRP/RAC researchers have proposed related models to predict stress-strain behavior and provided guidance for columns repaired by traditional FRP (Etxeberria et al., 2007; Huang et al., 2012; Silva et al., 2014; Xiao, 2018). In this guidance, the design oriented combined model proposed by Girgin and Girgin in 2015 also performs well in predicting the ultimate strengths and ultimate strains of NAC confined with conventional FRP Other researchers investigated the compressive behavior of FRP-confined RAC through a series of tests with parameters that determined the replacement ratio of RAC and the FRP jacket stiffness. (Xiao et al., 2005; Xiao et al., 2012; Chen et al., 2016). This research also showed that the existing stressstrain model of FRP-confined natural aggregate concrete (NAC) could be directly used to provide a reasonable prediction of the stress-strain behavior of FRP-confined RAC.

Although traditional FRP can effectively increase the ultimate load that a structure can withstand, tests have confirmed that the failure caused by FRP ruptures usually occurs when the researchers missed the limited time for evacuation. This situation can happen when an unpredictable natural disaster occurs, such as an earthquake. Therefore, the ductility of the traditional FRP composite structure needs to be re-evaluated. 
Recently, larger rupture strain (LRS) FRP has become popular due to its super ductile properties. Compared with traditional FRP composites (carbon FRP, glass FRP, and aramid FRP composites), LRS FRPs have a rupture strain of up to $5 \%$, which is very suitable for repairing or retrofitting a RAC after an earthquake (Dai et al., 2011; Bai et al., 2019). Therefore, using LRS FRP to repair damaged buildings after an earthquake should be a more economical and feasible solution (Bai et al., 2019) compared with traditional FRP confined concrete. However, only a few studies have focused on LRS FRP-confined concrete (Bai et al., 2017a; Bai et al., 2017b; Bai et al., 2019). Dai et al. (2011) tested the compressive stress-strain behavior of concrete confined with LRS FRP jackets made of embedded polyethylene naphthalate (PEN) and polyethylene terephthalate (PET) fibers in an epoxy resin matrix. Both the PEN and PET fibers are wellknown recycled materials, with PET usually obtained from recycled bottles. Compared with traditional Dai et al. (2011) found that LRS FRP could significantly improve the ductility of concrete due to a $5 \%$ fracture strain, which was $3 \%$ larger than that found in traditional FRP products. Dai et al. (2011) also developed an axial to lateral strain correction model based on their test data and a model developed by Jiang and Teng, 2007 for predicting the stress-strain behavior of LRS FRP-confined NAC. In 2014, Dai joined his co-authors, Bai and Teng, in another project, which presented the first model of LRS FRP-confined concrete under cyclic axial compression (Bai et al., 2014). This was a cyclic stress-strain model that combined an existing monotonic stress-strain model designed to predict unloading and reloading paths (Bai et al., 2014), and was also used to predict the behavior of LRS FRP-jacketed RC columns under seismic loading.

Despite past advances in LRS FRP-confined columns, current studies tend to only focus on the mechanical properties of FRPconfined undamaged concrete subjected to uniaxial compression tests (Girgin and Girgin, 2015; Li and Wu, 2016; Jiang et al., 2017a; Jiang et al., 2017b; Wu and Cao, 2017; Cao et al., 2018). Few studies have addressed the mechanical properties of FRP -onfined damaged recycled aggregate concrete (RAC). Because FRP's primary application is to serve as a confining material used to repair or strengthen degraded concrete structures, it is imperative that both the research community and those professionals in the concrete industry understand the mechanical properties of FRP-confined damaged concrete. Past studies were mainly limited to traditional FRP materials, due to the lack of references that could be used to compare the confinement effects of different FRP materials, especially that of LRS FRP, which presents the greatest deformability at the beginning of the confinement process. It is difficult to obtain information on the mechanical properties of RAs in a deteriorated state. Clear instructions need to be available on how to use FRP to repair damaged RAC to maximize the use of FRP materials and thereby improve the strength and ductility of concrete-based structures.

To address this research gap, this work presents a study of the experimental results associated with the axial compressive behavior of 58 FRP-confined RA concrete short columns with varying damage conditions. Concrete damage was achieved first
TABLE 1 | Test variables

\begin{tabular}{|c|c|c|c|c|c|c|c|c|}
\hline \multirow[t]{2}{*}{ FRP type } & \multirow[t]{2}{*}{ RA (\%) } & \multirow[t]{2}{*}{ FRP layer } & \multicolumn{5}{|c|}{ Preload level (\%) } & \multirow[t]{2}{*}{ Total } \\
\hline & & & 0 & 85 & 100 & -85 & -75 & \\
\hline \multirow[t]{5}{*}{ CFRP } & 0 & 1 & - & 2 & 2 & 2 & 2 & 8 \\
\hline & 50 & 1 & - & 2 & 2 & 2 & 2 & 8 \\
\hline & 50 & 2 & - & - & 2 & - & - & 2 \\
\hline & 50 & 3 & - & - & 2 & - & - & 2 \\
\hline & 100 & 1 & - & 2 & 2 & 2 & 2 & 8 \\
\hline \multirow[t]{9}{*}{ LRS FRP } & 0 & 1 & 2 & - & - & - & - & 2 \\
\hline & 0 & 2 & 2 & - & - & - & - & 2 \\
\hline & 0 & 3 & 2 & - & - & - & - & 2 \\
\hline & 50 & 1 & 2 & 2 & 2 & 2 & 2 & 10 \\
\hline & 50 & 2 & 2 & - & 2 & - & - & 4 \\
\hline & 50 & 3 & 2 & - & 2 & - & - & 4 \\
\hline & 100 & 1 & 2 & - & - & - & - & 2 \\
\hline & 100 & 2 & 2 & - & - & - & - & 2 \\
\hline & 100 & 3 & 2 & - & - & - & - & 2 \\
\hline \multicolumn{3}{|c|}{ Number of specimens } & & & & & & 58 \\
\hline
\end{tabular}

by preloading RA concrete with different degradation levels. According to the failure modes (ultimate strength and ultimate strain), the mechanical properties of RAC under CFRP and LRS FRP confinement were analyzed. In addition, from the perspectives of ductile behavior and energy absorption, this paper presents a study of the effects of degradation grade, FRP confinement stiffness, and the RA replacement ratio on key parameters of the stress-strain curve of confined RAC columns. The test results show that, compared with CFRP, the LRS FRPrepaired low-strength $\mathrm{RAC}$ columns show a higher bearing capacity and excellent deformation capacity.

\section{EXPERIMENTAL PROGRAM}

\section{Specimen Design}

In this work, uniaxial compression tests were conducted on concrete short columns with different recycled aggregate replacement ratios to study the stress-strain behavior of CFRP-repaired and LRS FRP-repaired concrete short columns. We prepared a total of 88 short columns with a diameter of $150 \mathrm{~mm}$ and a height of $300 \mathrm{~mm}$ in this study. Within these specimens, 24 unconfined concrete cylinders with different RA replacement ratios were tested to define the damage degree. Then, according to the defined damage, the remaining 58 concrete cylinders were preloaded to different damage levels first and then repaired by wrapping FRP around the columns for the compression test. The primary variables of the tests were concrete damage level $(85 \%, 100 \%,-85 \%$, and $-75 \%)$, recycled aggregates replacement ratio $(0 \%, 50 \%$, or $100 \%)$, FRP types (CFRP or LRSFRP), and FRP thickness (1, 2, or 3 layers). For the repaired specimens, the details of the test variables are listed in Table $\mathbf{1}$. Two identical specimens were manufactured for each specimen design.

\section{Materials Properties}

In this study, two different types of coarse aggregates were used in the concrete mix design, recycled aggregates (RAs) and natural 

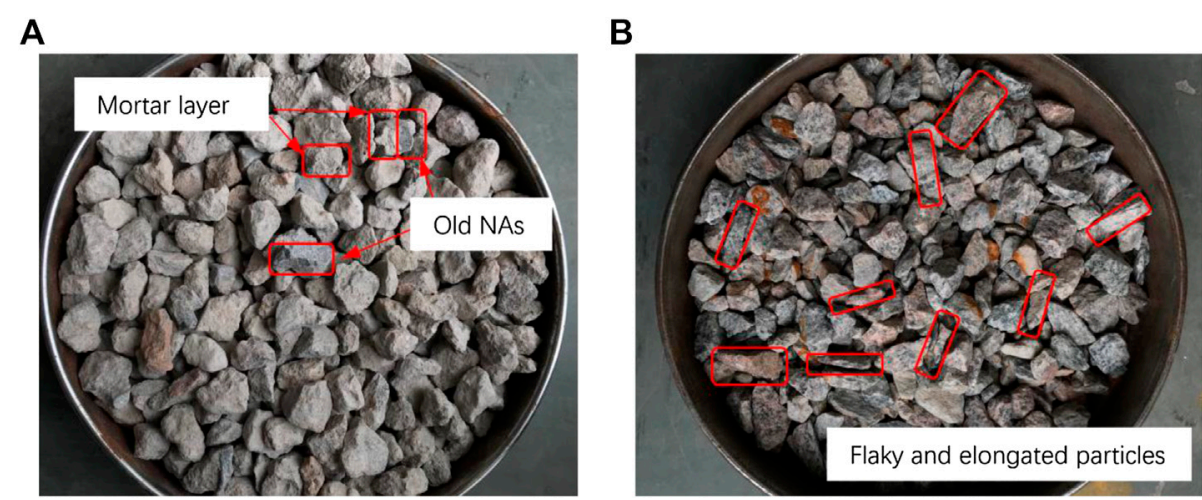

Figure 1 | Coarse aggregate appearance:(A) recycled. aggregates and (B) natural aggregates.

TABLE 2 | Properties of coarse aggregates

\begin{tabular}{lccc}
\hline Aggregate type & $\begin{array}{c}\text { Water absorption } \\
\text { (\%) }\end{array}$ & $\begin{array}{c}\text { Crush index } \\
\text { (\%) }\end{array}$ & $\begin{array}{c}\text { Size range } \\
\text { (mm) }\end{array}$ \\
\hline Natural aggregates & 1.35 & 17.9 & $5-31.5$ \\
Recycled & 6.42 & 26.3 & $5-31.5$ \\
aggregates & & &
\end{tabular}

TABLE 3 | Mix proportions of RAC with different replacement ratios

\begin{tabular}{lccc} 
Replacement ratio & $\mathbf{R}=\mathbf{0} \%$ & $\mathbf{R}=\mathbf{5 0} \%$ & $\mathbf{R}=\mathbf{1 0 0} \%$ \\
\hline Water $\left(\mathrm{kg} / \mathrm{m}^{3}\right)$ & 201 & 201 & 201 \\
Cement $\left(\mathrm{kg} / \mathrm{m}^{3}\right)$ & 380 & 380 & 380 \\
Natural aggregates $\left(\mathrm{kg} / \mathrm{m}^{3}\right)$ & 1,128 & 564 & 0 \\
Recycled aggregates $\left(\mathrm{kg} / \mathrm{m}^{3}\right)$ & 0 & 564 & 1,128 \\
Sand $\left(\mathrm{kg} / \mathrm{m}^{3}\right)$ & 691 & 691 & 691
\end{tabular}

aggregates (NAs), with continuously grading particle sizes ranging from 5 to $31.5 \mathrm{~mm}$. The RAs were from local construction demolished waste that had been crushed, cleaned, and graded. As shown in Figure 1A, a thin old mortar layer had adhered to the RAs, and the existence of this old mortar layer had been determined as the main cause of reducing the mechanical properties of the concrete (Poon et al., 2004). Figure 1B shows the appearance of NAs, set apart for the purpose of simulating low strength concrete conditions. Flaky and elongated particles were used as NAs. In this study, aggregates with an aspect ratio of 2:1 were defined as flaky and elongated aggregates, and the proportion of such aggregates accounted for $40 \%$ of the total. A previous study indicated that flaky and elongated particles lead to higher voids than cubical, rounded, spherical, or well-graded particles, and the aggregate shape factor plays a vital role in the design and performance of the concrete mix (Molugaram et al., 2014; Xianglin et al., 2014). The compressive strength of concrete decreases when increased flaky and elongated aggregates are a significant part of the mix (Ponnada, 2014; Jishou et al., 2015). The mechanical properties of these two types of aggregates were

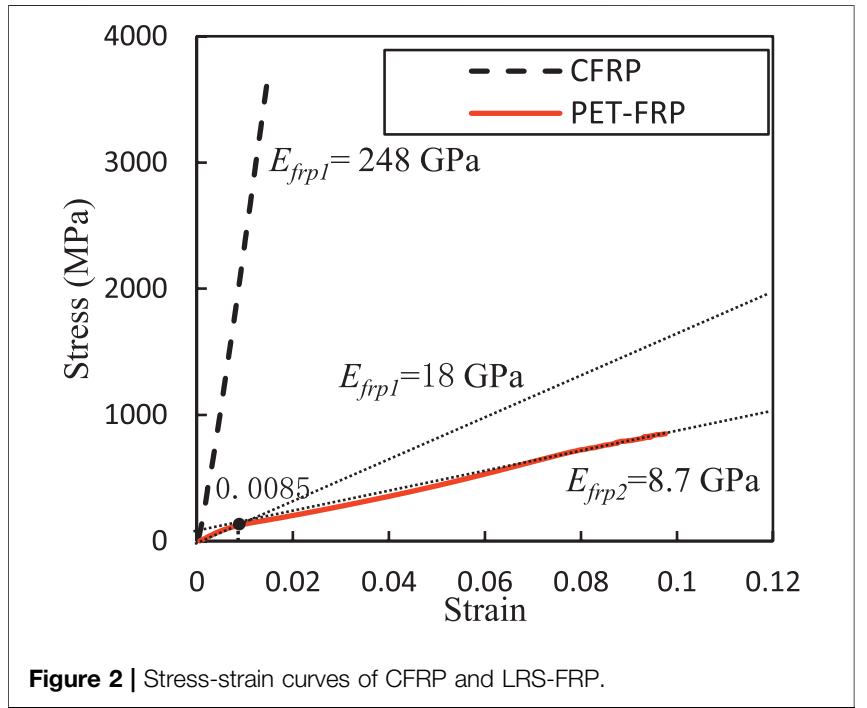

determined by two index factors: the crush index factor and the water absorption rate. These two factors have been validated as capable of affecting the strength of concrete (Zhang et al., 2017). The crush index can reflect the ability of the aggregate to resist crushing, and the water absorption rate directly affects the effective water-cement ratio of the concrete. As illustrated in Table 2, the water absorption rate of RAs was found to be around five times that of NAs (ASTM, 2012). Notably, the crush index factor $(17.9 \%)$ of NAs in this study is much larger that of good quality NAs that were usually given as around $4 \%$ in previous studies (Xiao et al., 2015; Chen et al., 2016; Zhou et al., 2016).

In this work, the above-mentioned NAs and RAs were used as coarse aggregates with different RA replacement ratios, which is defined as the mass replacement ratio. The NAs and RAs were combined with fine aggregate, Ordinary Portland cement, and water with a water-cement ratio of 0.5 . The details of the mix proportion are shown in Table 3. Specimens with the same replacement ratio were cast in the same batches of concrete to minimize the scattering of test results due to variations in concrete strength. Before casting, all aggregates were carefully 


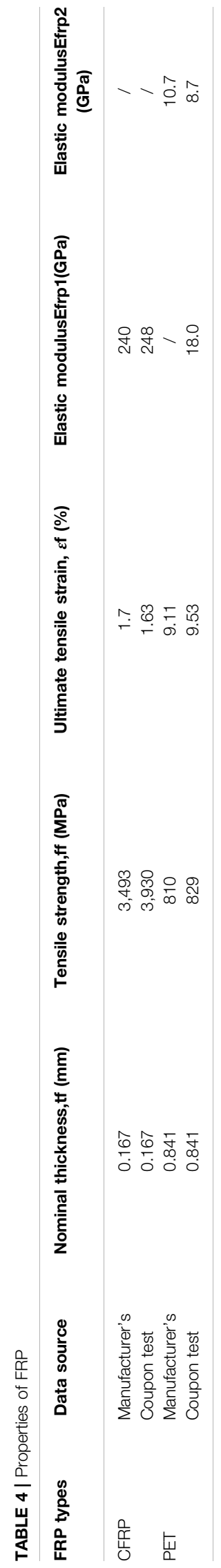

and completely dried in an oven to minimize the variation of water content. During the casting, although the same watercement ratio was adopted, the workability for flaky natural aggregate concrete (FNAC) was much better than that of RAC. This poor workability may be caused by the high-water absorption for the RAs. One day after casting, the specimens were removed from the molds and cured in a water tank at a constant temperature of $27 \mathrm{C}$ for 28 days. In each series, the 28 day unconfined concrete strength was obtained by the predamaged test, and the strength of this unconfined concrete with different replacement ratios were $17.1 \mathrm{MPa}$ for $0 \%$ replacement ratio, $18.2 \mathrm{MPa}$ for $50 \%$ replacement ratio, and $22.9 \mathrm{MPa}$ for $100 \%$ replacement ratio. It is noted that the strength for concrete with $100 \%$ RAs is higher than that of FNAC. This abnormal phenomenon may be caused by the high-water absorption for the RAs that reduces the effective watercement ratio and, in turn, slightly increases the concrete strength.

Both carbon fiber sheets (CFRP) and polyethylene terephthalate fiber (PET) sheets were used for repairing the pre-damaged specimens. Figure 2 shows the stress-strain behavior of both CFRP and LRS-FRP obtained from coupon tests according to the D3039 (ASTM, 1995) and D3039-M08 (ASTM, 2008), respectively. All the coupon test samples were $300 \mathrm{~mm}$ long and $50 \mathrm{~mm}$ wide. Table 4 shows the mechanical properties of FRP obtained from the coupon test results and the data provided by the manufacturer. For the LRS FRP composites, two different values of elastic modulus, namely the initial elastic modulus $\left(E_{f r p 1}\right)$ for the first linear portion and the second elastic modulus $\left(E_{f r p 2}\right)$ for the second linear part. Previous scholars have reported that such nonlinearity of stress-strain behavior is caused by the motion of amorphous phases and the sliding or failing of macromolecular chains in PET fibers (Lechat et al., 2011). A two-part epoxy resin, Lica-100, was used to impregnate fiber sheets and adhere them together through a wet lay-up procedure. The material properties of Lica-100 are provided in Table 5.

\section{Damage Definition}

In this study, the concrete damage degree factor $\delta$ is defined as the decrease in compressive strength between the compressive strength of the damaged concrete and the undamaged concrete, which is consistent with that proposed by Wu et al., 2014, which was given as:

$$
\delta=1-\frac{f_{c d}}{f_{c o}}
$$

where $f_{c o}$ and $f_{c d}$ are the peak strengths of concrete without and with damage, as shown in Figure 3.

The damage degree factor $\delta$ can be obtained by the preload test, and Figure 3 shows the process of the preload. The preload was applied according to the O-P-B path first, and then was immediately unloaded to zero stress $\mathrm{R}$. If the reloading is applied without any repair process, it will cause damage to the specimen along the R-H-C path, and the damaged peak 
TABLE 5 | Manufacturer's specified adhesive properties

\begin{tabular}{lcccc}
\hline Product name & $\begin{array}{c}\text { Tensile strength } \\
\mathbf{M P a}\end{array}$ & $\begin{array}{c}\text { Tensile modulus } \\
\mathbf{M P a}\end{array}$ & $\begin{array}{c}\text { Elongation } \% \\
\mathbf{M P a}\end{array}$ & $\begin{array}{c}\text { Bending strength } \\
\mathbf{M P a}\end{array}$ \\
\hline Lica-100 & 55.5 & 3.21 & 2.2 & 94 \\
\hline
\end{tabular}

strength $f_{c d}$ is located at point $\mathrm{H}$. According to Equation (1), the damage degree factor $\delta$ can be calculated from points $\mathrm{H}$ and $\mathrm{P}$. However, if FRP is used to repair the damaged short column, then the reload along the R-P'-A path will continue until it completely fails. This means that point $\mathrm{H}$ cannot be obtained for the FRPrepaired short column test. A method was proposed was Wu et al. (2014) to calculate the damaged degree index $\delta$ by establishing the relationship between the unloading point $\mathrm{B}$ and reloading peak point $\mathrm{H}$, which involves a stress excursion $\lambda$ that is defined as the total excursion of the stress along the stress-strain curve up to point B, which can be given as (Wu et al., 2014; Li et al., 2019a):

$$
\lambda=\frac{\int_{0}^{f_{c i}}|\mathrm{~d} \sigma|}{f_{c o}}= \begin{cases}\frac{f_{c i}}{f_{c o}} & \text { when } \varepsilon_{c i} \leq \varepsilon_{c o} \\ 1+\frac{f_{c o}-f_{c i}}{f_{c o}} & \text { when } \varepsilon_{c i}>\varepsilon_{c o}\end{cases}
$$

where $\sigma=$ axial stress; $f_{c i}$ and $\varepsilon_{c i}=$ stress and strain at unloading point $\mathrm{B}$; and $\varepsilon_{c o}=$ strain at the peak stress point $\mathrm{P}$.

In this study, the preloads were conducted by pre-compressing the concrete cylinder to a stress level equal to a certain peak strength percentage $(0 \%,+85 \%, 100 \%,-85 \%$, and $-75 \%)$, as shown in Figure 4. A value with a positive sign "+" indicates that the corresponding pre-compressed load is applied before the maximum strength is reached, while a negative sign "-” indicates that the applied load is in the declining phase after the peak load. Figure 4 shows specimens with preload negative stress levels $(-75 \%)$, which were much more heavily damaged than those with positive stress levels $(85 \%)$. Hence, significant cracks were seen on the specimens' surface. The data of $f_{c i}$ (Figure 3) can be easily obtained according to the preload test, which can be used to calculate the stress excursion $\lambda$. To ensure a reliable test data, two identical specimens were tested with the same stress level.

To determine the damage degree factor $\delta$, the point $\mathrm{H}\left(\varepsilon_{c d}\right.$ and $f_{c d}$ ) was obtained by reloading tests following the path $\mathrm{R}-\mathrm{H}-\mathrm{C}$, as shown in Figure 3. Figure 5 shows the test results of these reloading stress-strain curves for the unconfined concrete cylinders with different damage levels. Table 6 provides the key test data for all the damaged plain specimens. In this table, the three parts of the specimen ID specifies RA replacement ratio, preload level, and FRP ply number, respectively. For example, R100D85F0 specifies RA replacement ratio $100 \%$, preload level $85 \%$, and 0 -ply of FRP. This notation rule is also applicable to the repaired specimens shown in Table 7 and Table 8, where CF denotes CFRP repaired concrete, and LF denotes LRS-FRP repaired concrete. As shown in Figure 5, for specimens with different RA replacement ratios, the peak strength and

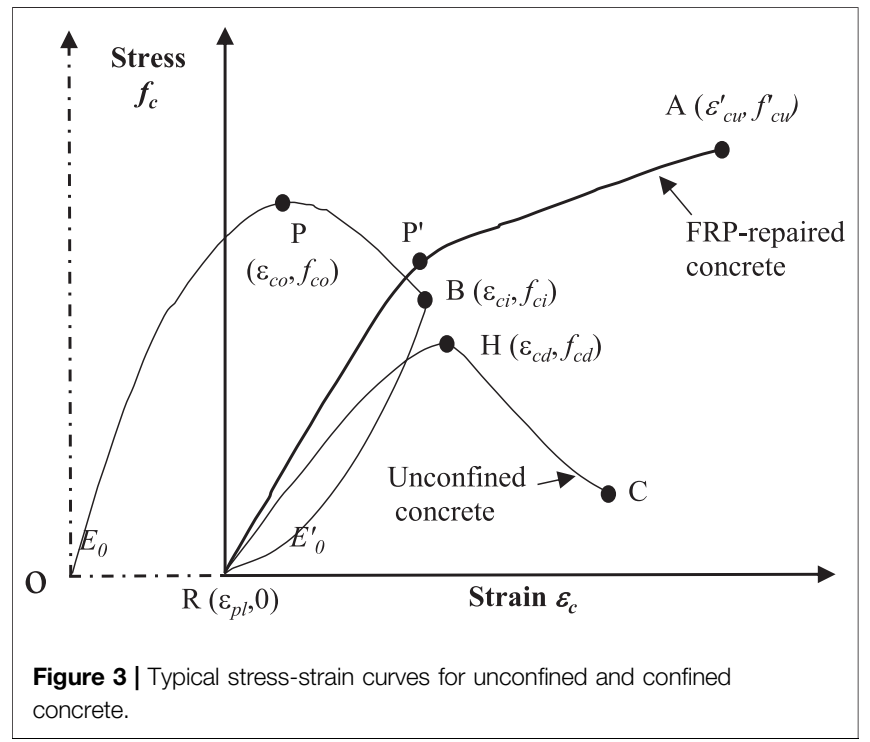

stiffness of concrete decreased with the increase of the preload level. Moreover, the strength drops significantly for the specimens with a minus preload level, such as specimens R0D-75F0, R50D-75F0, and R100D-75F0. Notably, specimen R100D85F0 yielded a lower strength than that of specimens R100D100F0 and R100D-85F0, as shown in Figure 5C. This phenomenon is attributed to the fact that unconfined concrete is easily affected by random crack patterns, which is a reasonable experimental error.

Using Equation (1) and (2), the relationship between the reloading peak load and strength reduction factor ( $\delta$ and $\lambda$ ) was established according to the method proposed byWu et al. (2014). Data from this test were plotted together with data obtained from the $\mathrm{Wu}$ et al. (2014) experiment. The data for the concrete specimens with different RA replacement ratios follow the trend line for the NA-damaged concrete. This means that the relationship between the damage level and stress excursion is independent when dealing with a recycled aggregate concrete specimen. For FRP-repaired specimens, the stress excursion is recorded (Equation (2)), and the actual damage can be calculated using the fitting formula in Figure 6.

To avoid a crack's sharp puncturing, a wrapped FRP sheet and high strength mortars with a water-cement ratio of 0.35 were first used to repair the cracks, providing a smooth surface for secure contact between the concrete and the FRP. Then, each specimen was wrapped by either a CFRP or LRS-FRP jacket using a manual lay-up process with an overlapping zone of $150 \mathrm{~mm}$ (Figure 7). To obtain a full-field strain distribution, a digital image 


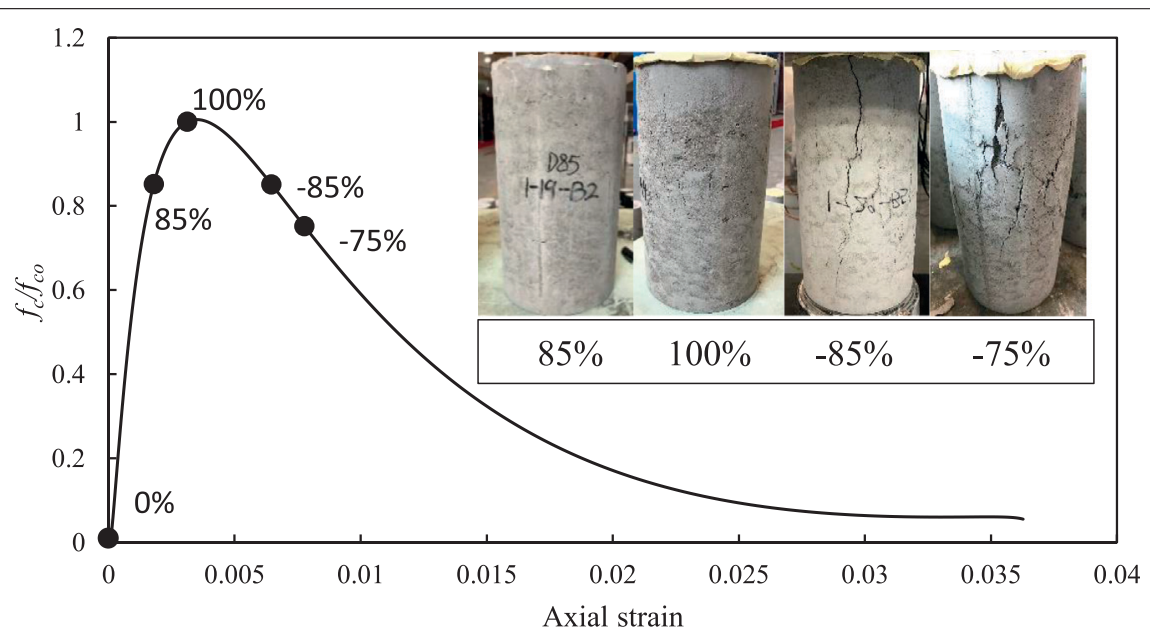

Figure 4 | Preload levels.
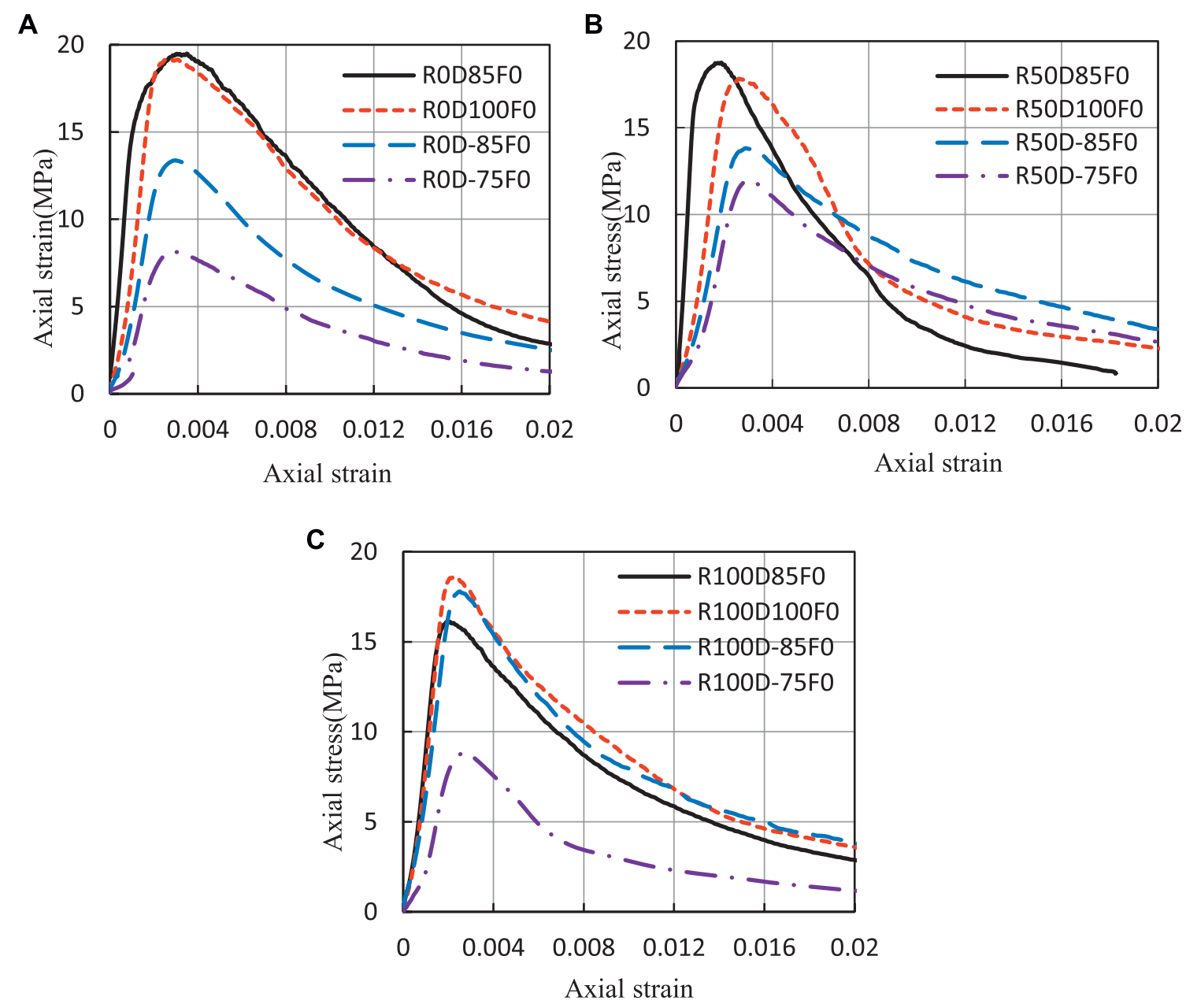

Figure 5 | Reloading stress-strain curves of specimens with different damage degree. 
TABLE 6 | Test results of unconfined specimens

\begin{tabular}{|c|c|c|c|c|c|}
\hline Specimens No. & $f_{c i}(\mathrm{MPa})$ & $f_{c d}(\mathrm{MPa})$ & $\varepsilon_{c d}(\%)$ & $\lambda(\%)$ & $\delta(\%)$ \\
\hline ROD85FO-1 & 14.40 & 16.35 & 0.29 & 84.03 & 4.63 \\
\hline R0D85FO-2 & 14.42 & 15.92 & 0.35 & 84.11 & 7.12 \\
\hline ROD100FO-1 & 18.49 & 17.85 & 0.28 & 99.84 & 3.59 \\
\hline ROD100FO-2 & 19.29 & 19.18 & 0.28 & 99.63 & 0.94 \\
\hline ROD-85FO-1 & 13.45 & 13.37 & 0.30 & 115.00 & 15.52 \\
\hline ROD-85FO-2 ${ }^{a}$ & - & - & - & - & - \\
\hline ROD-75FO-1 & 11.93 & 10.17 & 0.28 & 125.00 & 36.07 \\
\hline ROD-75FO-2 & 12.18 & 10.96 & 0.27 & 125.00 & 32.54 \\
\hline R50D85F0-1 & 15.48 & 18.76 & 0.17 & 81.45 & 1.28 \\
\hline R50D85F0-2 & 15.18 & 16.53 & 0.15 & 86.74 & 5.56 \\
\hline R50D100F0-1 & 18.07 & 17.83 & 0.21 & 99.89 & 1.45 \\
\hline R50D100F0-2 & 18.42 & 18.33 & 0.26 & 99.75 & 0.70 \\
\hline R50D-85F0-1 & 15.57 & 13.83 & 0.29 & 115.00 & 24.53 \\
\hline R50D-85F0-2 & 10.50 & 9.04 & 0.27 & 115.00 & 26.84 \\
\hline R50D-75FO-1 & 12.99 & 11.19 & 0.30 & 125.00 & 35.37 \\
\hline R50D-75FO-2 & 14.32 & 11.96 & 0.29 & 125.00 & 37.37 \\
\hline R100D85F0-1 ${ }^{a}$ & - & - & - & - & - \\
\hline R100D85F0-2 & 19.77 & 22.49 & 0.24 & 86.26 & 1.87 \\
\hline R100D100F0-1 & 26.18 & 25.24 & 0.18 & 99.02 & 4.53 \\
\hline R100D100F0-2 & 19.60 & 18.60 & 0.23 & 99.91 & 5.17 \\
\hline R100D-85F0-1 & 19.29 & 17.09 & 0.24 & 115.00 & 24.70 \\
\hline R100D-85F0-2 & 20.16 & 17.79 & 0.25 & 115.00 & 24.98 \\
\hline R100D-75FO-1 & 17.30 & 15.07 & 0.26 & 125.00 & 34.67 \\
\hline R100D-75FO-2 ${ }^{a}$ & - & - & - & - & - \\
\hline
\end{tabular}

${ }^{a}$ Specimens deemed invalid due to strain gauge damage.

correlation (DIC) system was adopted in this study. The nonoverlapped areas were spray-painted with white paint first, and then random small black spots were painted on the white base (Figure 7B). Moreover, all cylinders were capped with gypsum prior to testing to ensure uniform distribution of the compressive load.

In this study, the vertical displacement of all the specimens was measured by four $50-\mathrm{mm}$ linear variable differential transformers (LVDTs) mounted on aluminum frames fixed to the middle height of the specimen, and the gauge distance of the LVDTs was $185 \mathrm{~mm}$. For CFRP-confined concrete, eight strain gauges were mounted at the middle height of the specimen to measure the lateral strain and vertical strain. Locations of the specimen's strain gauges and LVDTs are shown in Figure 8A, where VSG and LSG indicate vertical and lateral strain gauges, respectively. The data of the vertical strain gauges were checked with the LVDT data to ensure accuracy in data collection during the test. For LRS FRPrepaired concrete cylinders, the lateral strain distribution on the nonoverlapping zone was recorded by the DIC system, as shown in Figure 8B. All specimens were tested using an MTS hydraulic loading machine under a concentric compression load with a maximum compression capacity of $3,000 \mathrm{KN}$ (Figure 9). During the test, the axial load, vertical displacement, and lateral strain data were collected simultaneously by the DEWESoft dynamic data logger system. For unconfined concrete cylinders, the specimen was tested with a load rate of $2 \mathrm{KN} / \mathrm{s}$ until the load reached $70 \%$ of unconfined concrete strength. Afterward, the load was changed to displacement control with a rate of $0.005 \mathrm{~mm} / \mathrm{s}$ until the specimens failed. For confined concrete cylinders, the load control of the two types of FRP was the same, but in the displacement control stage, the load rate was increased to $0.01 \mathrm{~mm} / \mathrm{s}$ until specimen failure.

\section{Failure Modes}

Figure 10 shows the failure mode of the unconfined FNAC with a replacement rate of $0 \%$. Clearly, the failure area of this concrete cylinder occurred in the middle of the specimen with no deep shear crack in the vertical direction. This is notable because the concrete was crushed severely, and some of the cracks penetrated the NAs and cut these aggregates into several pieces. This unexpected phenomenon is not consistent with existing research reports. Previous research (Poon et al., 2004; Kong et al., 2010; Kou et al., 2014) pointed out that the interface between the mortar and natural aggregate, also known as the interface transition zone (ITZ), is a weak point in concrete. Cracks usually extend along the weak ITZ, but they do not destroy the aggregate structure. However, from the failure mode in this study, we determined that the aggregate was weaker than the ITZ. This is due to the fact that the aggregates used in this work were mostly flaky particles, which are less resistant to concentrated loads. As a result, these slender particles can easily be damaged and cause cracks, which ultimately reduces the strength of the concrete.

The failure modes for CFRP and LRS FRP-confined concrete short columns are shown in Figure 11. Specimens with CFRP wrapping failed due to tensile rupture of the CFRP jacket at the column's midsection and outside the overlapping zone without debonding. The specimen's concrete behind the fiber rupture zone was crushed, and it is worth noting that the concrete crush degree was more severe for the specimen with less pre-damage level $(100 \%)$ compared with the specimen with a $-75 \%$ predamage level. This phenomenon is most likely because the predamage and existing cracking caused a less severe disintegration. In addition, the recycled aggregate concrete samples with different replacement ratios did not significantly change the morphology of the internal cracks in the concrete. For the LRS FRP-confined concrete short columns, the rupture also occurred at the specimen's midsection. However, the inner concrete of all the LRS-FRP specimens with different damage levels were fully crushed into powder due to the significant axial deformation. In addition, the FRP failure manner changed with the varying FRP layers; hence, specimens confined by 3-ply LRS FRP showed an unexpected debonding failure in the overlapping zone (Figure 11D) due to the inadequate bonding performance when the lateral expansion was larger for the specimen confined by one or two layers of the LRS FRP sheet.

\section{Axial Stress-Strain Curves}

A selection of typical axial stress-strain curves for three series of specimens is displayed in Figures 12-14, which offers a comparison of specimens with varying degrees of damage, RA replacement ratios, and FRP confinement levels. Furthermore, the LRS FRP-confined specimens with an RA replacement ratio of $50 \%$ were plotted together with the CFRP-wrapped specimens for 
TABLE 7 | Test results for CFRP confined specimens

\begin{tabular}{|c|c|c|c|c|c|c|c|c|c|c|}
\hline $\begin{array}{l}\text { Specimens } \\
\text { No. }\end{array}$ & $\begin{array}{c}\text { RA } \\
\%\end{array}$ & $\begin{array}{l}\text { Preload } \\
\text { level\% }\end{array}$ & $\begin{array}{l}\text { FRP } \\
\text { plies }\end{array}$ & $\delta$ & $\begin{array}{c}\boldsymbol{f}_{c o}\left(\boldsymbol{f}_{c c}\right) \\
\mathrm{MPa}\end{array}$ & $\begin{array}{c}\boldsymbol{f}_{c u}\left(\boldsymbol{f}_{c u}^{\prime}\right) \\
\mathrm{MPa}\end{array}$ & $\varepsilon_{c o}\left(\varepsilon_{c d}\right) \%$ & $\varepsilon_{c u}\left(\varepsilon_{c u}^{\prime}\right) \%$ & $\begin{array}{c}f_{c u} / f_{c o} \\
\left(f_{c u}^{\prime} / f_{c d}\right)\end{array}$ & $\begin{array}{c}\varepsilon_{c u} / \varepsilon_{c o} \\
\left(\varepsilon_{c u}^{\prime} / \varepsilon_{c d}\right)\end{array}$ \\
\hline RODOCF1-1 & 0 & 0 & 1 & - & 16.8 & 58.9 & - & 1.46 & 3.51 & - \\
\hline ROD0CF1-2 & 0 & 0 & 1 & - & 16.8 & 51.9 & - & 1.19 & 3.09 & - \\
\hline R0D85CF1-1 & 0 & 85 & 1 & 2.39 & 17.1 & 59.2 & 0.32 & 1.69 & 3.45 & 5.28 \\
\hline R0D85CF1-2 & 0 & 85 & 1 & 2.41 & 17.1 & 56.2 & 0.32 & 1.69 & 3.28 & 5.29 \\
\hline R0D100CF1-1 & 0 & 100 & 1 & 2.85 & 16.3 & 54.5 & 0.28 & 1.60 & 3.34 & 5.71 \\
\hline RoD100CF1-2 & 0 & 100 & 1 & 2.84 & 15.7 & 50.9 & 0.28 & 1.42 & 3.25 & 5.07 \\
\hline ROD-85CF1-1 & 0 & -85 & 1 & 20.44 & 17.3 & 55.2 & 0.31 & 1.45 & 3.19 & 4.69 \\
\hline ROD-85CF1-2 & 0 & -85 & 1 & 20.66 & 15.6 & 47.3 & 0.31 & 1.63 & 3.03 & 5.25 \\
\hline R0D-75CF1-1 & 0 & -75 & 1 & 35.97 & 15.9 & 42.7 & 0.28 & 1.35 & 2.68 & 4.83 \\
\hline ROD-75CF1-2 ${ }^{a}$ & 0 & -75 & 1 & 32.36 & 13.1 & 38.8 & 0.28 & 2.38 & 2.97 & 8.51 \\
\hline R50D0CF1-1 & 50 & 0 & 1 & - & 18.6 & 55.2 & - & 1.51 & 2.97 & - \\
\hline R50D0CF1-2 & 50 & 0 & 1 & - & 18.6 & 53.9 & - & 1.41 & 2.90 & - \\
\hline R50D85CF1-1 & 50 & 85 & 1 & 2.42 & 19.0 & 52.1 & 0.17 & 1.41 & 2.74 & 8.30 \\
\hline R50D85CF1-2 & 50 & 85 & 1 & 2.42 & 19.0 & 63.0 & 0.17 & 1.39 & 3.31 & 8.18 \\
\hline R50D100CF1-1 & 50 & 100 & 1 & 2.84 & 14.9 & 53.5 & 0.24 & 1.55 & 3.60 & 6.44 \\
\hline R50D100CF1-2 & 50 & 100 & 1 & 2.84 & 15.8 & 57.4 & 0.24 & 1.52 & 3.64 & 6.34 \\
\hline R50D100CF2-1 & 50 & 100 & 2 & 2.82 & 15.7 & 80.1 & 0.24 & 2.60 & 5.11 & 10.82 \\
\hline R50D100CF2-2 & 50 & 100 & 2 & 2.84 & 15.0 & 85.0 & 0.24 & 2.63 & 5.66 & 10.97 \\
\hline R50D100CF3-1 & 50 & 100 & 3 & 2.84 & 19.0 & 104.9 & 0.24 & 2.95 & 5.52 & 12.30 \\
\hline R50D100CF3-2 & 50 & 100 & 3 & 2.85 & 16.8 & 99.9 & 0.24 & 2.91 & 5.95 & 12.13 \\
\hline R50D-85CF1-1 & 50 & -85 & 1 & 20.38 & 18.3 & 52.5 & 0.28 & 1.56 & 2.87 & 5.58 \\
\hline R50D-85CF1-2 & 50 & -85 & 1 & 20.80 & 18.6 & 51.6 & 0.28 & 1.41 & 2.77 & 5.05 \\
\hline R50D-75CF1-1 & 50 & -75 & 1 & 32.69 & 13.1 & 44.1 & 0.30 & 0.94 & 3.36 & 3.15 \\
\hline R50D-75CF1-2 & 50 & -75 & 1 & 32.57 & 13.9 & 48.3 & 0.30 & 1.71 & 3.49 & 5.71 \\
\hline R100D0CF1-1 & 100 & 0 & 1 & - & 23.2 & 57.4 & - & 1.29 & 2.47 & - \\
\hline R100D0CF1-2 & 100 & 0 & 1 & - & 23.2 & 51.9 & - & 0.98 & 2.24 & - \\
\hline R100D85CF1-1 & 100 & 85 & 1 & 2.44 & 22.9 & 59.0 & 0.21 & 1.26 & 2.57 & 5.99 \\
\hline R100D85CF1-2 & 100 & 85 & 1 & 2.42 & 22.9 & 63.5 & 0.21 & 1.42 & 2.77 & 6.76 \\
\hline R100D100CF1-1 & 100 & 100 & 1 & 2.85 & 27.8 & 62.7 & 0.20 & 1.34 & 2.25 & 6.69 \\
\hline R100D100CF1-2 & 100 & 100 & 1 & 2.84 & 23.6 & 58.3 & 0.20 & 1.28 & 2.47 & 6.40 \\
\hline R100D-85CF1-1 & 100 & -85 & 1 & 21.08 & 19.3 & 53.5 & 0.25 & 1.41 & 2.77 & 5.63 \\
\hline R100D-85CF1-2 & 100 & -85 & 1 & 22.11 & 23.9 & 57.5 & 0.25 & 1.28 & 2.40 & 5.13 \\
\hline R100D-75CF1-1 & 100 & -75 & 1 & 31.38 & 23.0 & 50.9 & 0.14 & 1.46 & 2.21 & 10.40 \\
\hline R100D-75CF1-2 & 100 & -75 & 1 & 32.36 & 20.9 & 48.8 & 0.14 & 1.13 & 2.33 & 8.10 \\
\hline
\end{tabular}

aspecimens that experienced load eccentricity.

Instrumentation and testing for repaired damaged concrete columns.

comparison. In these figures, the axial stress value was obtained by dividing the axial load value by the cross-sectional area of the concrete specimen, and the axial strain was calculated by dividing the average of the four LVDT readings by the gauge length of $185 \mathrm{~mm}$, and the obtained data from the LVDTs was also checked by DIC data. It is obvious from these figures that the stress-strain behavior of the FRP-confined RAC is similar to that of the FRPconfined FNAC in terms of curve shape. The stress-strain curve presents a noticeable bilinear relationship, which is comprised of a first elastic linear branch followed by a nonlinear transition zone and linear-to-peak stress. The curves of the two identical specimens with the same nominal parameters agree well with each other, except for the R50D85CF1 specimens. This was most likely caused by the condition of the heavily damaged specimens and the subsequent inconformity during the repair process. Details of the experimental test results from these stress-strain curves are summarized in Tables $\mathbf{7}$ and $\mathbf{8}$, which list the key test data, such as ultimate stress $\left(f_{c c}\right)$ and ultimate axial strain $\left(\varepsilon_{c u}\right)$, unconfined concrete strength $\left(f_{c o}\right)$ and its corresponding strain $\left(\varepsilon_{c o}\right)$, and ultimate strength enhancement ratios $\left(f_{c u} / f_{c o}\right)$ and strain enhancement ratios $\left(\varepsilon_{c u} / \varepsilon_{c o}\right)$. The effects of these main factors (damage degree, RA replacement ratio, and confinement level) on the stress-strain behavior of these repaired columns are discussed in the following sections.

\section{DISCUSSION}

\section{Effect of Pre-damage Level}

Figure 12 compares the stress-strain curves of specimens with different pre-damage levels. It can be noted that the curves in each figure are for specimens with the same FRP thickness and RA replacement ratio. Regarding the stress-strain curve, for predamage caused random crack patterns, even the unloading stress is the same. This randomness leads to the scattering of the stress-strain curves, as shown in Figure 12, even for identical specimens. For specimens with the same RA replacement ratio, the ultimate strength of the CFRP-repaired 
TABLE 8 | Test results for LRS FRP confined specimens

\begin{tabular}{|c|c|c|c|c|c|c|c|c|c|c|}
\hline $\begin{array}{l}\text { Specimens } \\
\text { No. }\end{array}$ & R \% & $\begin{array}{c}\text { Preload } \\
\text { level } \\
(\%)\end{array}$ & $\begin{array}{l}\text { FRP } \\
\text { plies }\end{array}$ & $\delta$ & $\begin{array}{r}\boldsymbol{f}_{c o}\left(\boldsymbol{f}_{c d}\right) \\
(\mathrm{MPa})\end{array}$ & $\begin{array}{c}\boldsymbol{f}_{c u}\left(\boldsymbol{f}_{c u}^{\prime}\right) \\
(\mathrm{MPa})\end{array}$ & $\varepsilon_{c o}\left(\varepsilon_{c d}\right)(\%)$ & $\varepsilon_{c u}\left(\varepsilon_{c u}^{\prime}\right)(\%)$ & $\begin{array}{c}\boldsymbol{f}_{c u} / \boldsymbol{f}_{c o} \\
\left(\boldsymbol{f}_{c u}^{\prime} /\right. \\
\left.\boldsymbol{f}_{c d}\right)\end{array}$ & $\begin{array}{c}\varepsilon_{c u} / \varepsilon_{c o} \\
\left(\varepsilon_{c u}^{\prime} /\right. \\
\left.\varepsilon_{c d}\right)\end{array}$ \\
\hline RODOLF1-1 & 0 & $0 \%$ & 1 & 0 & 17.17 & 67.33 & 0.29 & 4.49 & 3.92 & 15.49 \\
\hline RODOLF1-2 & 0 & $0 \%$ & 1 & 0 & 17.17 & 67.59 & 0.29 & 4.53 & 3.94 & 15.62 \\
\hline RODOLF2-1 & 0 & $0 \%$ & 2 & 0 & 17.17 & 96.74 & 0.29 & 4.75 & 5.63 & 20.60 \\
\hline RODOLF2-2 & 0 & $0 \%$ & 2 & 0 & 17.17 & 79.88 & 0.29 & 3.71 & 4.65 & 13.31 \\
\hline RODOLF3-1 & 0 & $0 \%$ & 3 & 0 & 17.17 & 137.72 & 0.29 & 6.79 & 8.02 & 23.40 \\
\hline RODOLF3-2 & 0 & $0 \%$ & 3 & 0 & 17.17 & 139.24 & 0.29 & 6.76 & 8.11 & 23.32 \\
\hline R50D0LF1-1 & 50 & $0 \%$ & 1 & 0 & 15.87 & 59.61 & 0.27 & 3.04 & 3.76 & 11.28 \\
\hline R50D0LF1-2 & 50 & $0 \%$ & 1 & 0 & 15.87 & 71.33 & 0.27 & 6.20 & 4.49 & 22.96 \\
\hline R50D0LF2-1 & 50 & $0 \%$ & 2 & 0 & 15.87 & 84.86 & 0.27 & 5.18 & 5.35 & 19.18 \\
\hline R50D0LF2-2 & 50 & $0 \%$ & 2 & 0 & 15.87 & 81.14 & 0.27 & 6.40 & 5.11 & 23.71 \\
\hline R50D0LF3-1 & 50 & $0 \%$ & 3 & 0 & 15.87 & 137.52 & 0.27 & 7.49 & 8.67 & 27.76 \\
\hline R50D0LF3-2 & 50 & $0 \%$ & 3 & 0 & 15.87 & 131.35 & 0.27 & 7.72 & 8.28 & 28.59 \\
\hline R50D0LF1-1 & 50 & $85 \%$ & 1 & 2.55 & 15.87 & 67.88 & 0.16 & 6.01 & 4.28 & 37.54 \\
\hline R50D0LF1-2 & 50 & $85 \%$ & 1 & 2.46 & 15.87 & 62.63 & 0.16 & 5.21 & 3.95 & 32.56 \\
\hline R50D100LF1-1 & 50 & $100 \%$ & 1 & 2.85 & 18.28 & 61.44 & 0.24 & 6.25 & 3.36 & 26.03 \\
\hline R50D100LF1-2 & 50 & $100 \%$ & 1 & 2.85 & 18.28 & 70.34 & 0.24 & 5.57 & 3.85 & 23.20 \\
\hline R50D100LF2-1 & 50 & $100 \%$ & 2 & 2.82 & 18.28 & 98.54 & 0.24 & 6.25 & 5.39 & 26.02 \\
\hline R50D100LF2-2 & 50 & $100 \%$ & 2 & 2.84 & 18.28 & 102.87 & 0.24 & 6.91 & 5.63 & 28.78 \\
\hline R50D100LF3-1 & 50 & $100 \%$ & 3 & 2.84 & 18.28 & 130.38 & 0.24 & 8.65 & 7.13 & 36.03 \\
\hline R50D100LF3-2 & 50 & $100 \%$ & 3 & 2.82 & 18.28 & 133.43 & 0.24 & 8.40 & 7.30 & 34.99 \\
\hline R50D-85LF1-1 & 50 & $-85 \%$ & 1 & 17.93 & 18.32 & 58.72 & 0.28 & 4.00 & 3.21 & 14.29 \\
\hline R50D-85LF1-2 & 50 & $-85 \%$ & 1 & 19.87 & 18.32 & 56.65 & 0.28 & 3.28 & 3.09 & 11.73 \\
\hline R50D-75LF1-1 & 50 & $-75 \%$ & 1 & 31.98 & 18.20 & 61.57 & 0.30 & 8.46 & 3.38 & 28.19 \\
\hline R50D-75LF1-2 & 50 & $-75 \%$ & 1 & 31.18 & 18.20 & 53.61 & 0.30 & 4.88 & 2.95 & 16.25 \\
\hline R100DOLF1-1 & 100 & $0 \%$ & 1 & 0 & 23.11 & 62.24 & 0.20 & 4.41 & 2.69 & 22.05 \\
\hline R100D0LF1-2 & 100 & $0 \%$ & 1 & 0 & 23.11 & 53.73 & 0.20 & 3.18 & 2.32 & 16.42 \\
\hline R100DOLF2-1 & 100 & $0 \%$ & 2 & 0 & 23.11 & 86.99 & 0.20 & 5.93 & 3.76 & 30.05 \\
\hline R100D0LF2-2 & 100 & $0 \%$ & 2 & 0 & 23.11 & 91.25 & 0.20 & 6.72 & 3.95 & 33.92 \\
\hline R100D0LF3-1 & 100 & $0 \%$ & 3 & 0 & 23.11 & 120.99 & 0.20 & 8.69 & 5.24 & 44.49 \\
\hline R100D0LF3-2 & 100 & $0 \%$ & 3 & 0 & 23.11 & 122.45 & 0.20 & 8.08 & 5.30 & 40.39 \\
\hline
\end{tabular}

RAC generally decreases as the pre-damage level increases. Notably, the reduction in the ultimate stress is not apparent when the damage degree is reached before the peak strength of unconfined concrete $(0 \%, 85 \%$, and $100 \%)$. However, for the specimens with damage levels exceeding the peak load of unconfined concrete $(-85 \%$ and $-75 \%)$, the reduction in ultimate stress is significant; the second stiffness drops as well. This phenomenon reveals that concrete damage develops faster after the peak strength of unconfined concrete, which leads to further stress reduction even after FRP has repaired the damaged concrete. The CFRP repair effectiveness is highly dependent on the concrete damage condition. Furthermore, under the same replacement ratio, the initial stiffness of specimens with different pre-damage levels also decreases with increasing damage levels. An obvious decrease occurs in specimens with a $-75 \%$ preload level. In addition, for LRS FRP-confined specimens, as shown in Figure 12C, the ultimate strength also decreases gradually with increasing damage levels. However, the initial stiffness is almost constant. Under large deformations, although the inner concrete has been crushed completely, the second branch behavior is highly dependent on the pre-damage condition. Furthermore, the start of the transition zone gradually decreases with the increasing preload level.
It is worth noting that, for the specimens repaired by CFRP, the ultimate strain gradually increases with the increase of the pre-damage level. This phenomenon has been reported by Li et al. (2019a) and is attributed to the existing pre-damage cracks' uniform dilation behavior, which avoids the stress concentration that could cause the FRP immature fracture, reducing the FRP confinement effectiveness. However, compared with CFRP-repaired specimens, the ultimate strain of LRS FRP-confined concrete shows an opposite trend, that is, the ultimate strain decreases as the damage increases. This observation could be explained by investigating the failure mode of LRS FRP-confined concrete, as shown in Figure 11 where the rupture zone of LRS FRP is more concentrated for specimens with more extensive damage (R50D-85LF1) compared to a specimen with less damage (R50D100LF3). Due to the extreme rupture strain characteristics of LRS FRP, the axial strain of FRP-confined concrete could reach around 6\%, indicating that the concrete was completely crushed. In this high axial deformation condition, the dilation behavior becomes more local and concentrated for the specimen with heavy pre-damage, which causes a local rupture of LRS FRP, thereby reducing the ultimate strain. In conclusion, FRP confinement is useful for repairing damaged concrete, and the pre-damage significantly affects repair effectiveness. LRS FRP is a 


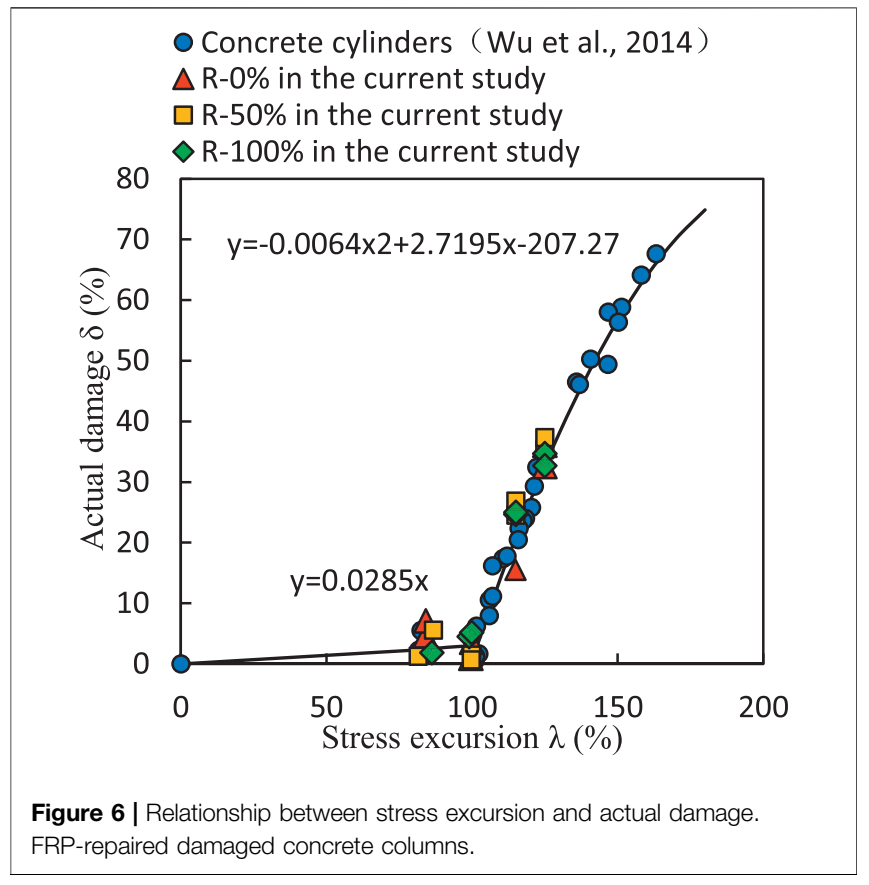

A

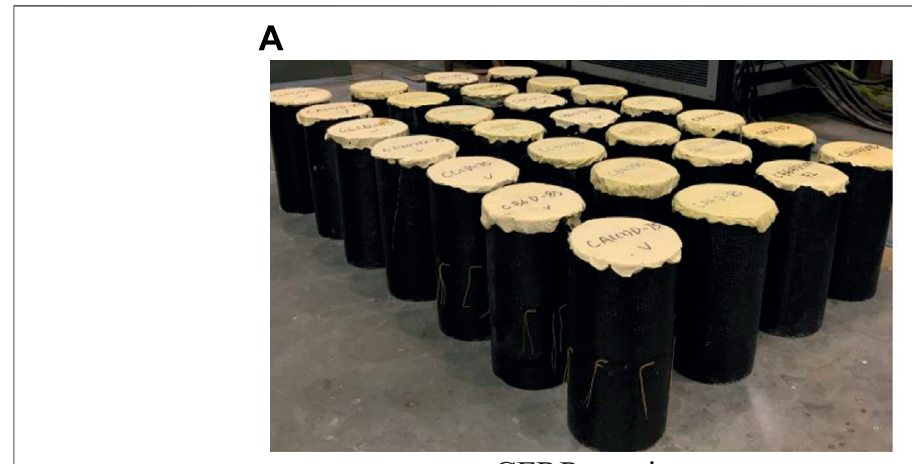

CFRP repair

Figure 7 | Repaired specimens with CFRP and LRS FRP. more efficient strengthening material, and the deformation enhancement far exceeds that of CFRP-repaired concrete.

\section{Effect of Recycled Aggregates Replacement Ratio}

Previous studies have indicated that the mechanical behavior of FRP-confined RAC is highly related to the recycled aggregates' replacement ratio. This helps establish that the peak strength of FRP-confined RAC decreases with the increase of the RA replacement ratio. Moreover, the strength variation is dependent on the RA water absorption ratio (Zhao et al., 2015; Zhou et al., 2016). In order to further study the influence of the RA replacement ratio on the damaged concrete repaired by FRP, the stress-strain curves of CFRPconfined specimens with the same preload level but different RA replacement ratios were grouped. Figure 13 shows the comparison of specimens that had different replacement ratios but the same preload level and jacket stiffness. With the increase of the replacement ratio from $50 \%$ to $100 \%$, the ultimate strength of confined concrete with different pre-damage levels shows a decrease in strength and an increase in ultimate strain. However,

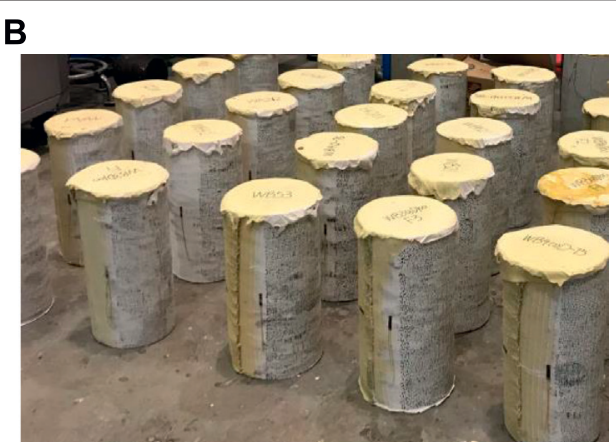

LRS FRP repair
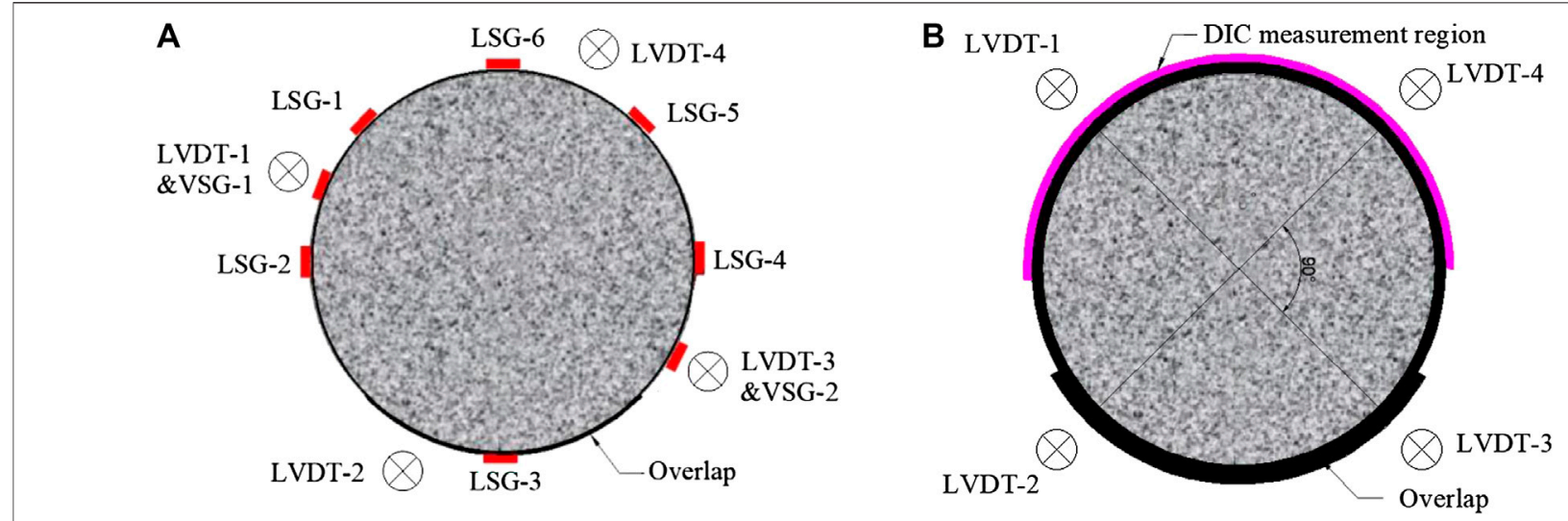

Figure 8 | LVDTs and strain gauge distribution: (A) CFRP- confined concrete and (B) LRS FRP-confined concrete. 
the axial stress-strain curve of the specimen with a 50\% RA replacement ratio is almost consistent with the FNAC $(0 \%$ replacement ratio). Notably, the ultimate strength of specimens with a $100 \%$ RA replacement ratio was higher than that of the other two specimens with a low replacement ratio. This observation is contrary to the conclusions of previous studies (Zhao et al., 2015; Chen et al., 2016; Zhou et al., 2016), where the

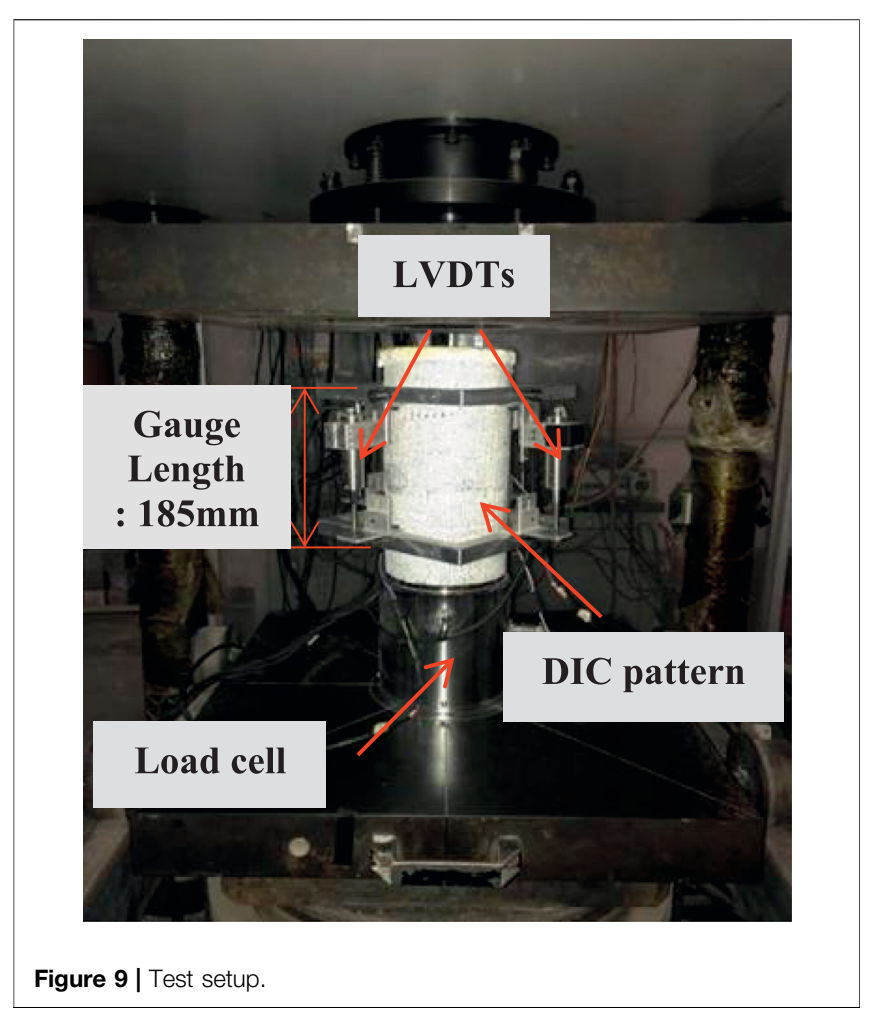

strength of concrete decreased with the increase of the replacement rate of RAs. It can be attributed to the fact that more elongated and flaky particles made up the NAC, and the compressive strength was significantly reduced compared to ordinary natural aggregates. This observation is consistent with the results of $\mathrm{Li}$ et al. (2019b), in which poor-quality aggregates were adopted as well. In addition, another reason may be caused by the higher water absorption ratio for the Ras, as shown in Table 2, with the free water absorbing into the Ras, leading to a lower actual water-cement ratio, which in turn results in higher concrete strength. For further comparison, the stressstrain curve of the LRS FPR-confined specimens (preload level = $0 \%$ ) are illustrated in Figure 3G, H, 13F,. As with CFRP-confined $\mathrm{RAC}$, the stress of specimens with an 100\% RA replacement ratio was greater than for the other two specimens, when the axial strain was less than $1.5 \%$, which is almost the failure point for CFRP-confined RAC. However, the ultimate strength of the LRSconfined RAC is inversely proportional to the replacement rate of RAC. This interesting finding is attributed to what governs the strength of the concrete: aggregates or mortar. At the small axial strain region (less than $1.5 \%$ ), mortar plays a more important role toward resisting the axial load, and the speimen with an 100\% RA replacement ratio shows higher stress because it has a low effective water-cement ratio. However, with the increase of axial strain, RAC confined by LRS FRP has been completely crushed, and mortar has been crushed into powder. In this case, aggregates take over from mortar to bear the load, and the specimen with a $0 \%$ RA replacement ratio shows a higher ultimate strength. This important finding reveals the effect of aggregates on the strength of FRP-confined concrete at different stages. Generally, the test results show that jacketing FRP to concrete can effectively make up for the decrease in compressive strength due to poor aggregate material. Previous experimental results of found that the transition region of the stress-strain curves of FRP-confined RAC is smoother than the curves of FRP-

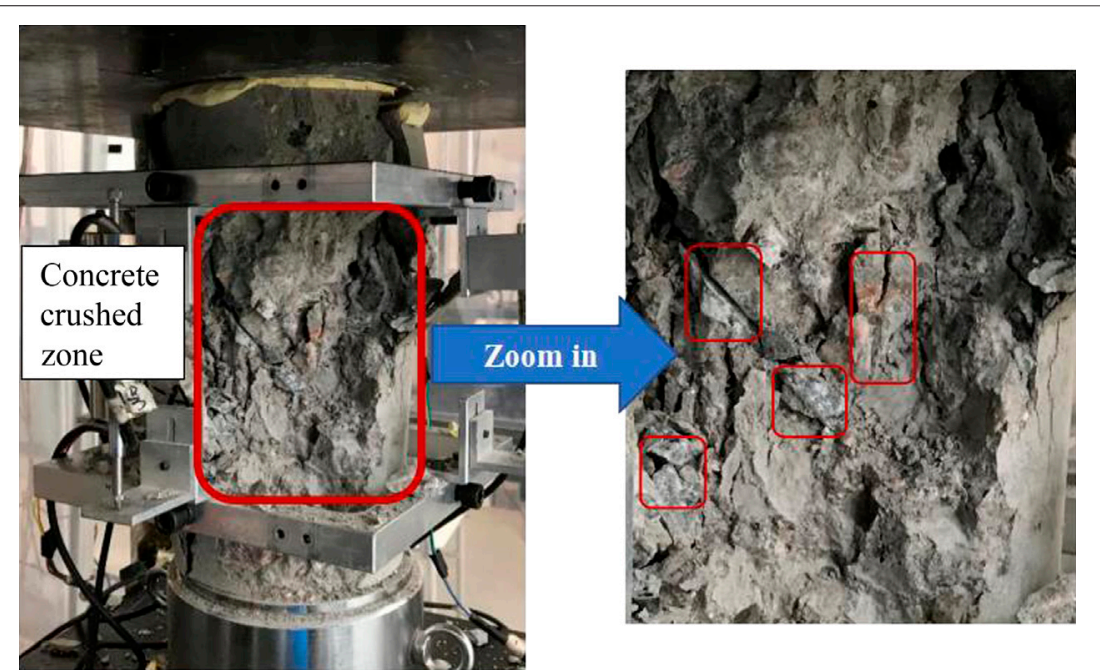

Figure 10 | Failure mode for unconfined low-strength concrete. 


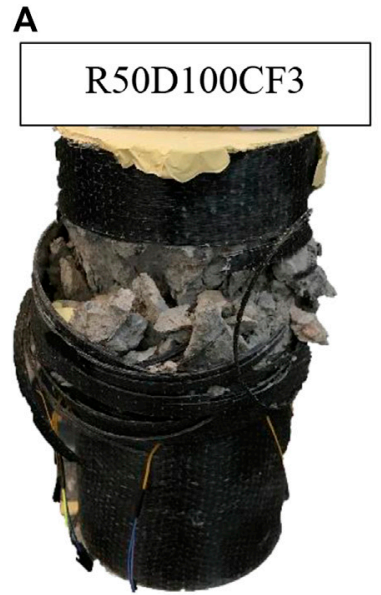

CFRP-D100

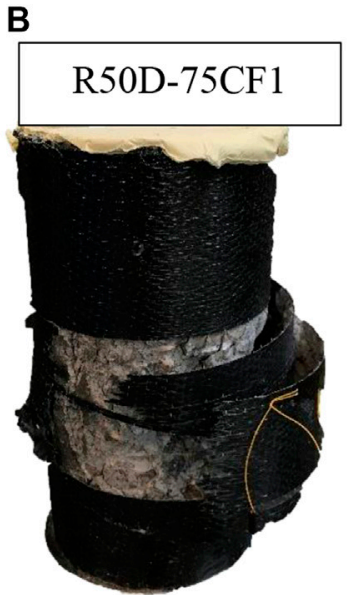

CFRP-D-77

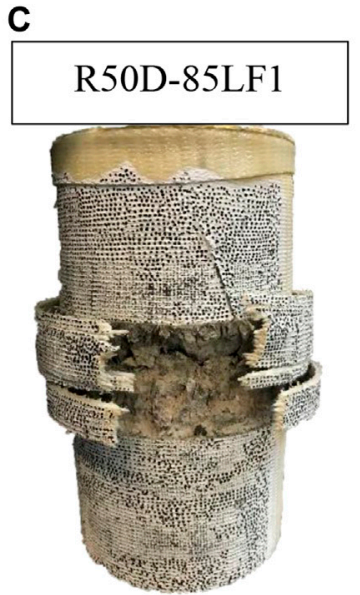

LRS FRP 1-ply

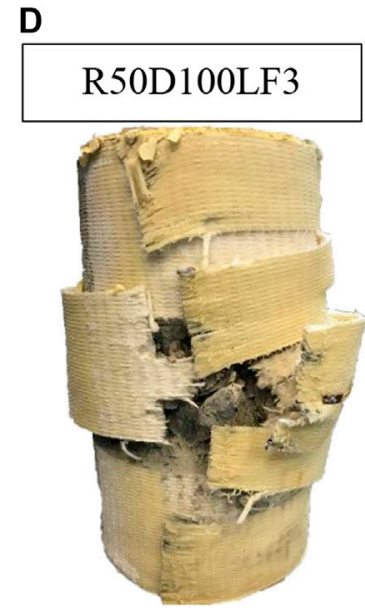

LRS FRP 3-ply

Figure 11 | Failure modes for FRP-confined specimens with different FRP types.
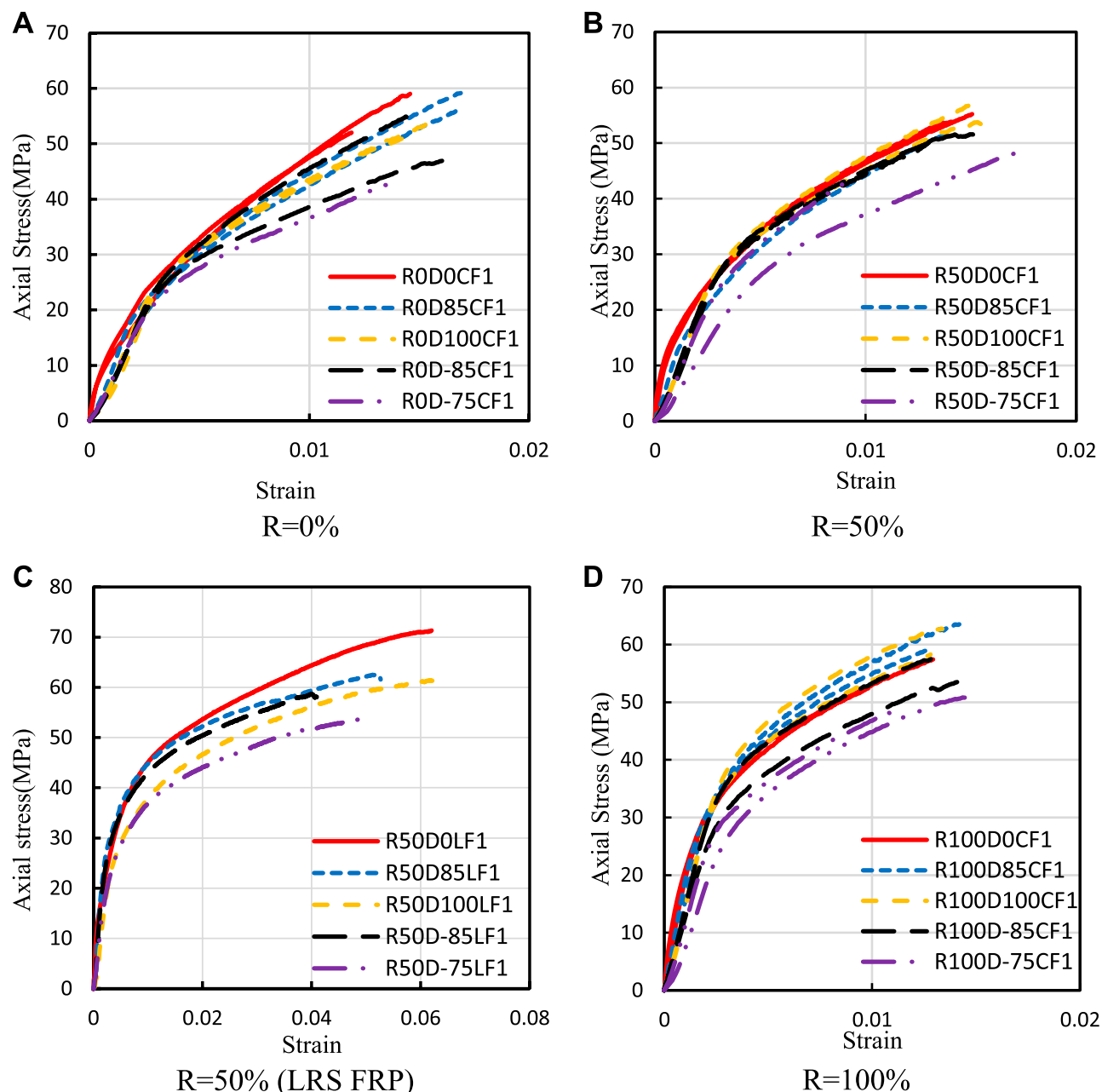

Figure 12 | Stress-strain curves with different pre-damage levels: (A) $R=0 \%$, (B) $R=50 \%$, (C) $R=50 \%$ (LRS FRP), (D) $R=100 \%$. 

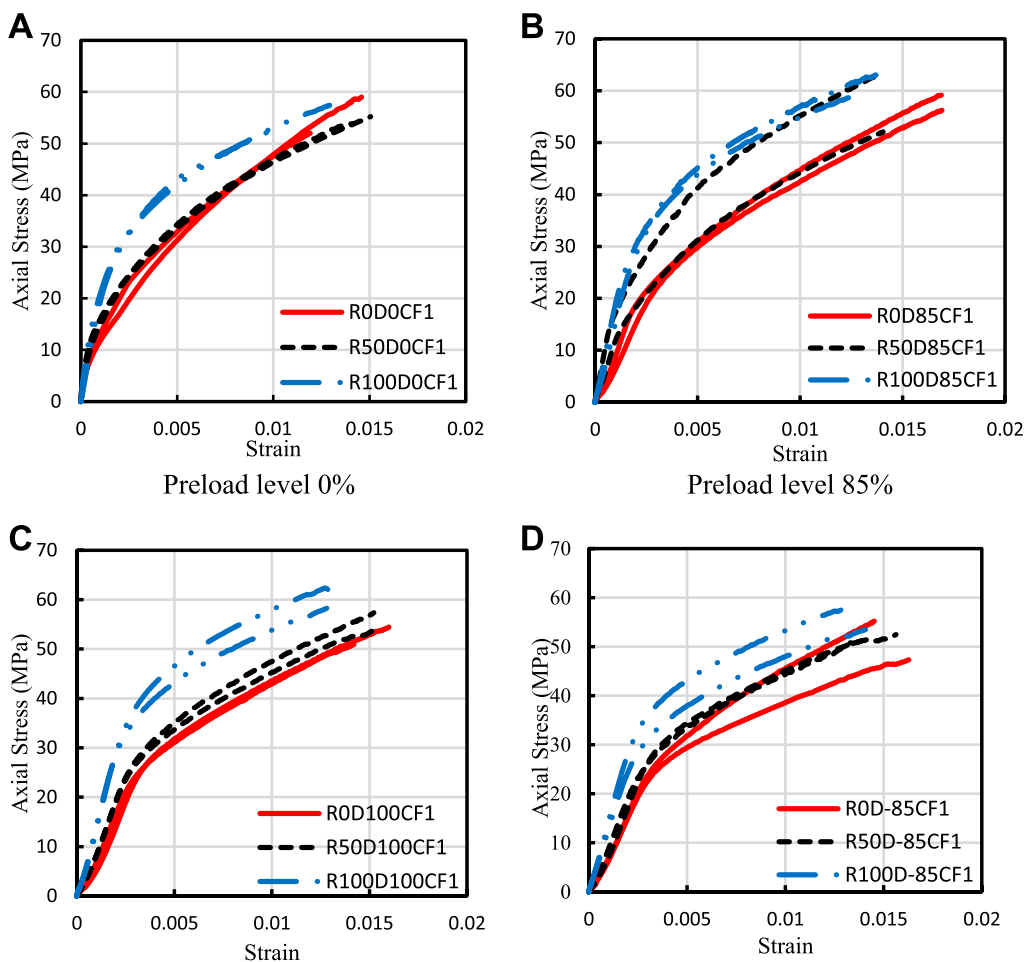

Preload level 85\%

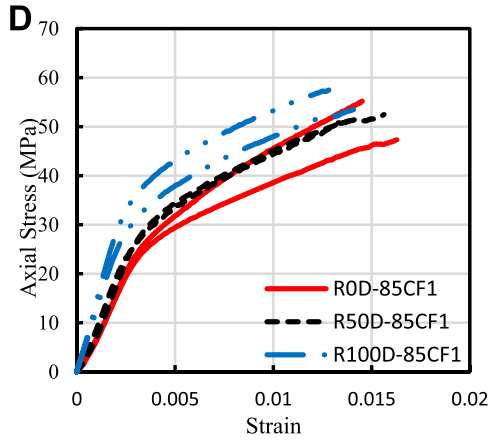

Preload level $100 \%$

Preload level $-85 \%$

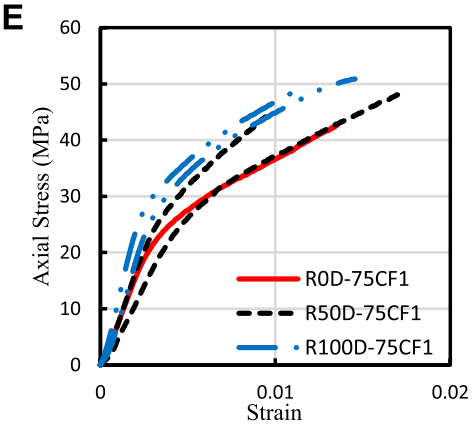

$\mathbf{F}$

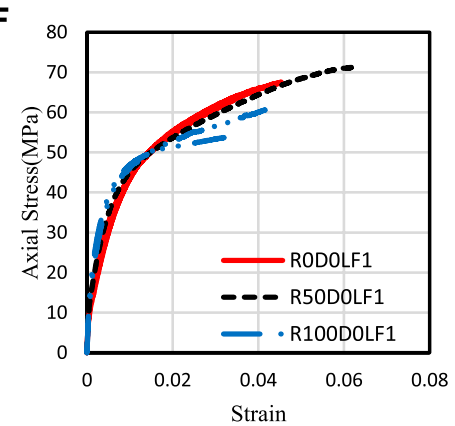

Preload level $-75 \%$

One layer LRS FRP

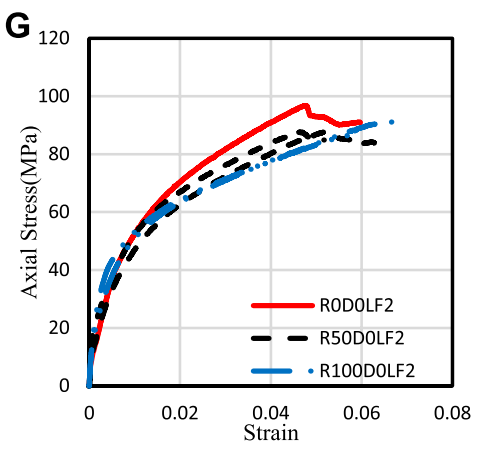

Two layers LRS FRP

\section{H}

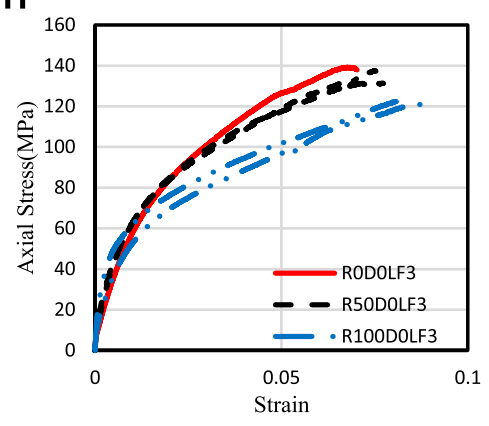

Three layers LRS FRP

Figure 13 | The stress-strain curve with different RAs replacement ratios.

confined FNAC (Zhao et al., 2015). In this study, however, by a careful inspection in Figure 3B, D, 13A, the opposite trend was found. The stress-strain behavior of FRP-confined RAC shows that the transition area is more extended when the RA replacement ratio decreases, and this phenomenon is more evident in the specimens with a $0 \%$ RA replacement ratio, as shown when 

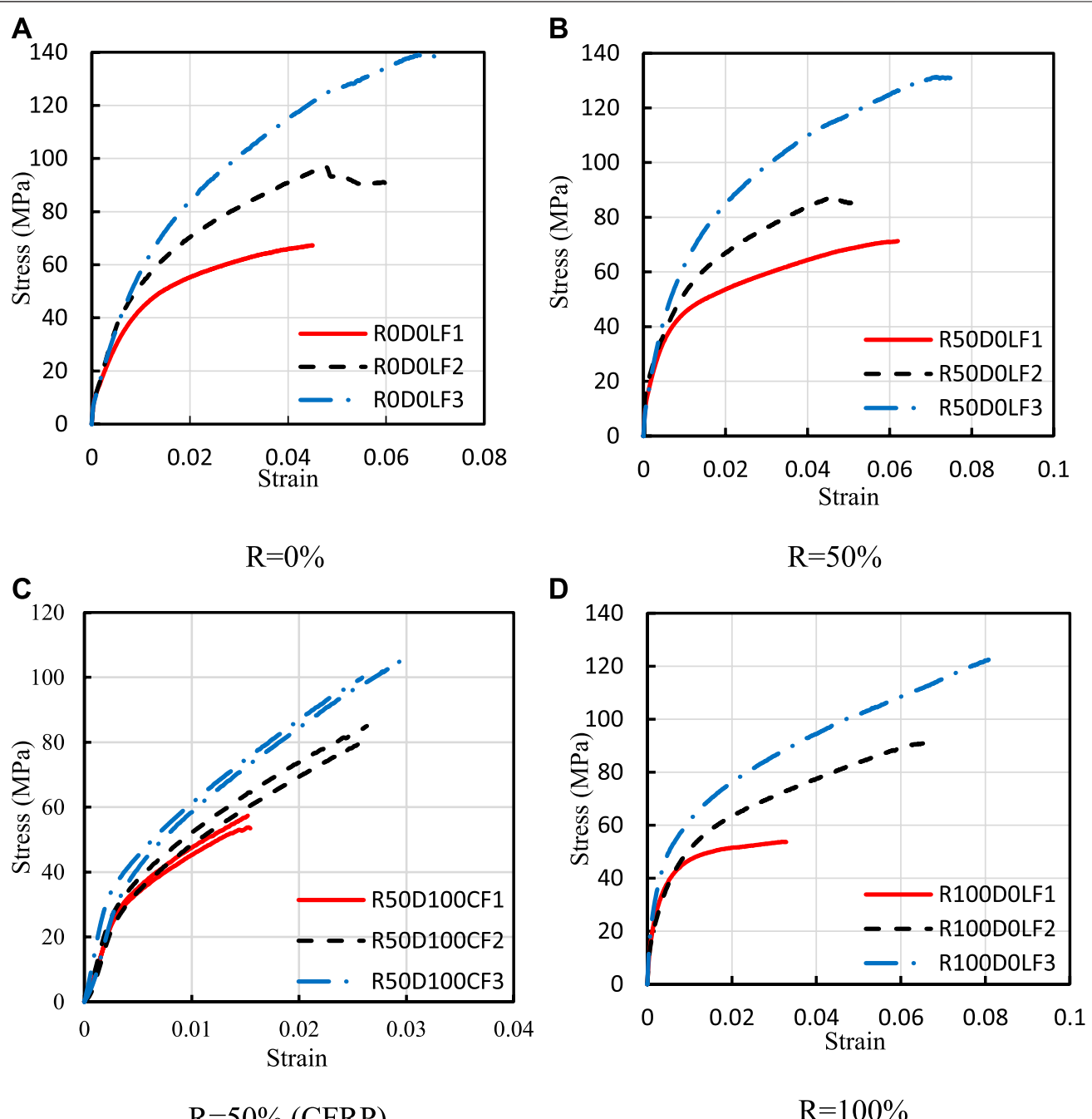

Figure 14 | The stress-strain curve with different FRP layers.

comparing Figure 13A, D. This abnormal observation is also caused by the mortar strength rather than the aggregate quality. As discussed previously, at the transition region, the strength of mortar governs the cracks spread, not the aggregate quality. Hence, the specimen with an $100 \%$ RA replacement ratio, which shows a higher compressive strength due to the low effective water cement ratio compared with specimen with $0 \% \mathrm{RA}$, shows a higher and shaper transition stress.

\section{Effect of FRP Confinement Stiffness}

Existing research indicates that this strain hardening phenomenon is primarily affected by confinement stiffness and the strength of unconfined concrete; moreover, experimental and analytical studies (Jiang et al., 2016; Mohammadi and Wu, 2017; Li et al., 2018) have concluded that it is the stiffness of the confining system that controls the slope behind the transition zone, not the ultimate confining pressure. Figure 14 presents the stress-strain curves of the specimens with different FRP thicknesses, and the confinement stiffness for the same FRP material differs in thickness. For both CFRP- and LRS FRP-confined concrete, it can be observed that the initial axial stiffness of the elastic stage varies little with the confinement stiffness. In other words, when concrete is in its early elastic stages, the FRP confinement has little effect on the axial stress-strain curve due to the limited concrete expansion. However, as the load gradually increased and cracks formed, the axial stressstrain curve became highly dependent on the confinement stiffness of FRP, which shows that the slope of the second branch of stress-strain curves increases when the confinement stiffness increases. The terminated points of stress-strain curves are highly related to the FRP thickness, even for the specimens with different RA replacement ratios and pre-damage levels, and the ultimate strength and strain will increase with the increasing FRP thickness. This observation indicates that increasing FRP jacketing is an 


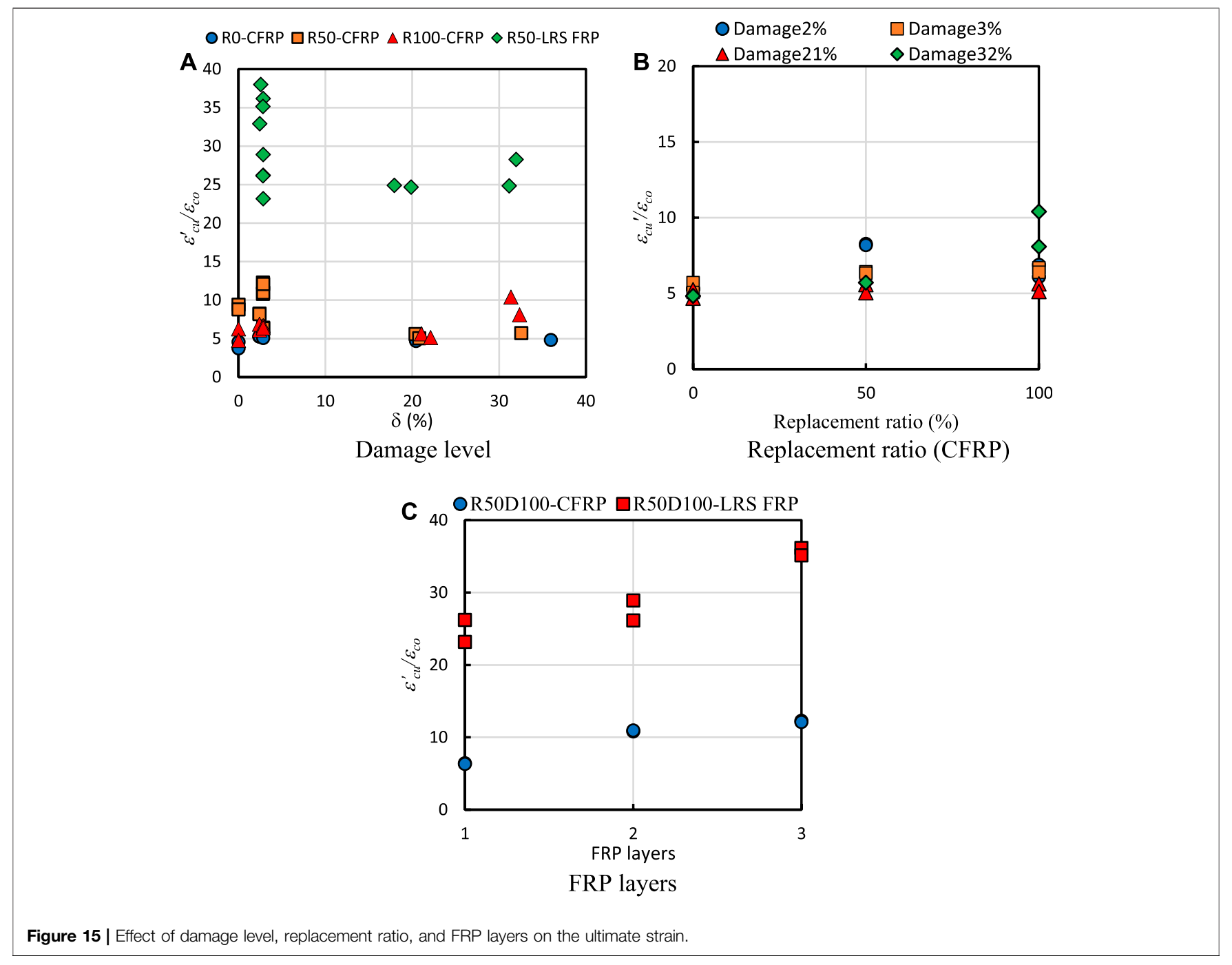

effective method to repair damaged concrete. This applies especially for the LRS FRP confined concrete, as shown in the comparison of Figures 14C, D. Ultimate strain could be reached at $8 \%$, which provides greater deformability and more structural safety for concrete. In addition, the transition zone for specimens with more FRP confinement is obviously longer than that of the specimen with less FRP confinement. This is attributed to the fact that increasing the FRP confining pressure postponed the concrete crack development and enlarged the transition zone.

\section{DUCTILITY EVALUATION OF CFRP- AND LRS FRP-CONFINED CONCRETE}

\section{Ultimate Strain}

In this study, the ductility index is presented as the ultimate strain ratio, that is, the $\varepsilon_{c u}^{\prime}$ (the ultimate axial strain for FRP confined concrete) to the $\varepsilon_{c o}$ (the corresponding axial strain of peak strength for plain concrete). Details of the strain ratio for all confined specimens are summarized in Table 7 and Table 8. Figure 15 shows the influences of the damage level, replacement ratio, and FRP layer on the ultimate strain ratio. As can be seen from this figure, the ultimate strain ratio for the LRS FRP-repaired damaged RA specimens is significantly larger than that of CFRP-confined specimens, showing that LRS FRP can dramatically enhance the ductile behavior of damaged concrete. Moreover, as can be seen from Figure 15A, the ultimate strain ratio of CFRP-confined concrete remains constant, regardless of the degree of damage. Similarly, as shown in Figure 15B, the RA replacement ratio has little effect on the ultimate strain ratio for the specimen with a damage level of less than $21 \%$. For the heavily damaged concrete specimens (32\%), however, the ultimate ratio increases with the increasing Ras' replacement ratio. In addition, the stress-strain curves are shown in Figure $15 \mathrm{C}$, and the $\varepsilon_{\mathrm{cu}} / \varepsilon_{\mathrm{co}}$ ratios given in Table 7 illustrate that the ultimate axial strain of the specimens increases with the increased FRP thickness (number of layers), which implies that increasing the FRP 


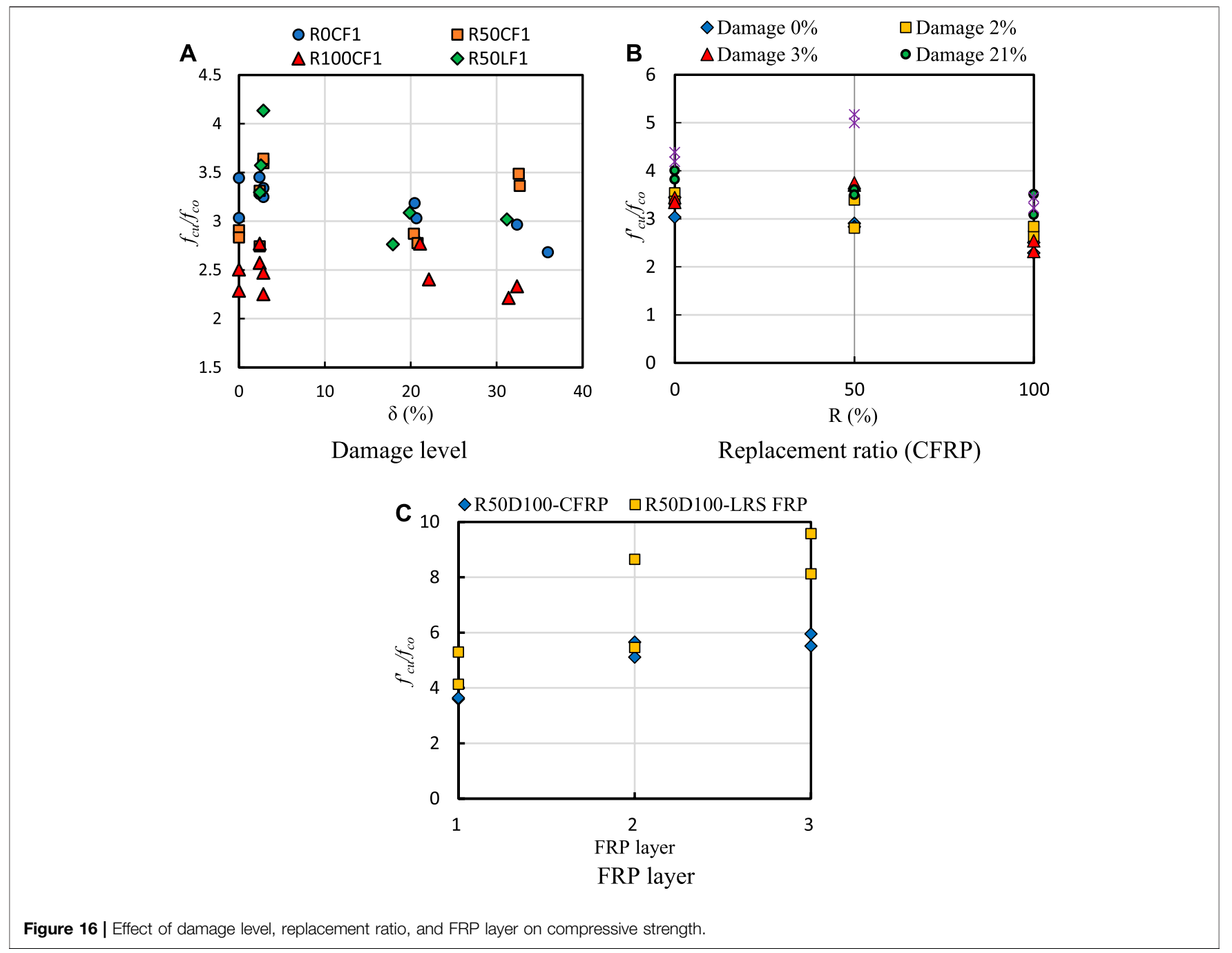

layers could benefit the ductility performance of the FRPconfined RAC. Overall, the ductility of concrete under LRS FRP-confined RA concrete is significantly better than that of CFRP-confined specimens.

\section{Ultimate Strength}

In order to more intuitively observe the changing trend of the ultimate strength ratio, Figure 16 illustrates the factors (replacement ratio, damage degree, and FRP confinement stiffness) that affect the ultimate strength, separately. The experimental results show that the ultimate strength of the specimens tends to decrease slightly as the pre-damaged level and the replacement ratio of RAs increase (Figures 6B, 16A, and 17A). It is worth noting that the strength of a specimen with a $50 \%$ replacement ratio is significantly higher than that of a specimen with a $0 \%$ and $100 \%$ replacement ratio. This phenomenon is consistent with the results of Zhou et al. (2010) and Chen et al. (2016), who investigated the performance of RAC columns with different RA replacement ratios under a large eccentric compression load. When the ratio of substitution is over $50 \%$ and less than $100 \%$, the RAC load capacity does not decrease but, instead, increases. This could be caused by the water absorption ability of RA concrete and the proportion of RAs; hence, a balance of these two factors could lead to a higher concrete strength, especially for the heavily damaged condition. In addition, for both CFRP and LRS FRP, as shown in Figure 16C, increasing the number of FRP layers is an effective way to enhance the ultimate strength ratio, and it is more effective for LRS FRP-repaired specimens.

\section{Absorption of Strain Energy}

Regarded as seismic retrofitting or repairing, the ability of energy absorption is a vital index that reflects the energy dissipation capacity of a structure under the action of the seismic load. Figure $\mathbf{1 7}$ presented the total amount of energy absorption (the area underneath the stress-strain curve) for the two types of FRP jackets when rupture failure occurred. It can be seen from Figure 17A that the strain energy absorbed by the 


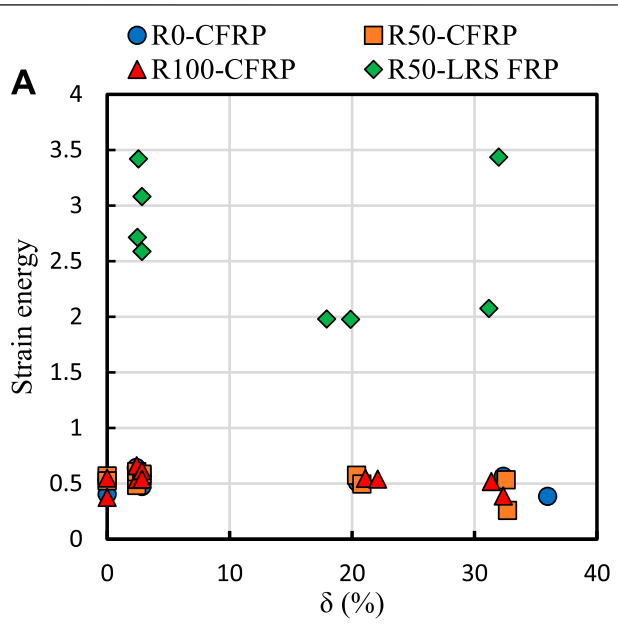

Strain energy vs. damage level

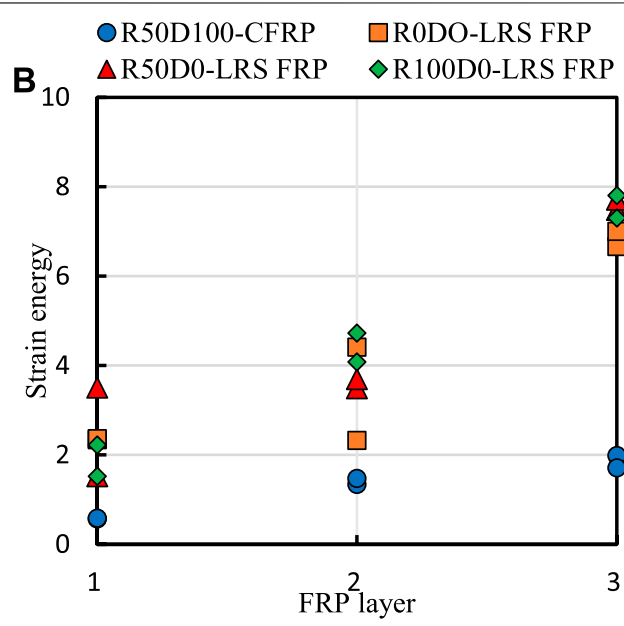

Strain energy vs. FRP number of layers

Figure 17 | Effect of damage level and FRP layers on strain energy.

specimen wrapped by CFRP is maintained at about $5 \%$, and the influence of the degradation level can be negligible. However, the energy absorbed by the LRS FRP tends to decrease as the damage level increases. The energy absorbed by the damage level at $20 \%$ and $30 \%$ is reduced compared to the energy absorbed by the $0 \%$ damage level. In general, the energy absorbed by LRS FRP at the same damage level is about four times that of CFRP. Figure 17B shows that the energy absorbed ability of confined specimens increases as the number of FRP layers increases, and the increase in the strain energy absorbed by CFRP is moderate compared to that absorbed by LRS FRP. Since the stiffness of LRS FRP is much smaller than that of CFRP, the fracture strain at which LRS FRP is subjected to at the limit load is also greater. Therefore, the large strain capability of PET FRP is very suitable for seismic reinforcement.

\section{CONCLUSIONS}

This paper presents compressive behavior through a series of axial compression tests on CFRP- and LRS FRP-confined damaged RAC, where the replacement ratio of coarse aggregate, damage level, FRP types, and the stiffness of FRP are vital variables. The following observations and conclusions can be drawn from this work:

(1) The strength gain by FRP jacketing for pre-damaged RAC is dependent on the pre-damage levels. The existing damage in concrete does not weaken the FRP confinement effectiveness, but reducing the unconfined concrete strength leads to a decrease in the ultimate strength of FRP-repaired RAC with increasing damage levels.

(2) The compressive behavior of FRP-confined damaged RAC is similar to that of FRP-confined FNAC. The FRP jacket stiffness has a significant effect on the stress-strain behavior of FRP-repaired damaged RAC. Furthermore, increasing the thickness (number of layers) of FRP is an effective way to enhance the mechanical properties of damaged RAC.

(3) 3) The quality of aggregates plays a vital role in the stressstrain behavior of FRP-confined RAC. Due to the poor quality of the NAs used in this test, and the high-water absorption ability of RAs, the CFRP-confined concrete with a higher RA ratio has a higher compressive strength than FNAC, since an effective low water-cement ratio results in the higher compressive strength of unconfined concrete. However, for the LRS FRP-confined RAC, the ultimate strength (at around 6\% axial strain) of FNAC was higher than that of RAC due to the fact that the mortar had been crushed into powder and the aggregates mainly govern the damaged concrete strength.

(4) CFRP and LRS FRP both show good performance in improving the compressive strength and ultimate strain of degraded short columns. LRS FRP showed an excellent ability to improve the ductility of a structure. The ultimate strain ratio and energy absorption ability of LRS-repaired RAC was around five times greater than that of the CFRPconfined RAC. This outstanding ductility performance gives the LRS FRP a substantially higher potential for seismic retrofitting or repairing of concrete structures than CFRP. 


\section{DATA AVAILABILITY STATEMENT}

The raw data supporting the conclusions of this article will be made available by the authors, without undue reservation.

\section{AUTHOR CONTRIBUTIONS}

$\mathrm{YZ}$ carried out the original draft preparation, formal analysis, and review and editing of the manuscript. ZC carried out the experimental work. XL was involved in the methodology and resources, while PL was responsible for conceptualization and project administration. YZ provided constructive comments on the work and performed editing.

\section{REFERENCES}

ASTM (2012). Standard test method for density, relative density (specific gravity), and absorption of coarse aggregate. West Conshohocken, PA.

ASTM (2008). Standard test method for tensile properties of polymer matrix composite materials. PA: West Conshohoken.

ASTM (1995). Standard test method for tensile properties of polymer matrix composite materials. D3039/D3039M-95, Annual book of ASTM standards, West Conshohocken, PA.

Bai, Y.-L., Dai, J.-G., Mohammadi, M., Lin, G., and Mei, S.-J. J. C. S. (2019). Stiffness-based design-oriented compressive stress-strain model for largerupture-strain (LRS) FRP-confined concrete. Compos. Struct. 223(SEP.), 110953-110951. doi:10.1016/j.compstruct.2019.110953

Bai, Y.-L., Dai, J.-G., and Ozbakkaloglu, T. (2017a). Cyclic stress-strain model incorporating buckling effect for steel reinforcing bars embedded in FRPconfined concrete. Compos. Struct. 182, 54-66. doi:10.1016/j.compstruct.2017. 09.007

Bai, Y. L., Dai, J. G., and Teng, J. G. (2017b). Buckling of steel reinforcing bars in FRP-confined RC columns: an experimental study. Construct. Build. Mater. 140, 403-415. doi:10.1016/j.conbuildmat.2017.02.149

Bai, Y. L., Dai, J. G., and Teng, J. G. (2014). Cyclic compressive behavior of concrete confined with large rupture strain FRP composites. J. Compos. Construct. 18(1), 12. doi:10.1061/(asce)cc.1943-5614.0000386

Barnhouse, P. W., and Srubar, W. V. (2016). Material characterization and hydraulic conductivity modeling of macroporous recycled-aggregate pervious concrete. Constr. Build. Mater. 110, 89-97. doi:10.1016/j. conbuildmat.2016.02.014

Behera, M., Bhattacharyya, S. K., Minocha, A. K., Deoliya, R., and Maiti, S. (2014). Recycled aggregate from C\&D waste \& its use in concrete - a breakthrough towards sustainability in construction sector: a review. Construct. Build. Mater. 68, 501-516. doi:10.1016/j.conbuildmat.2014.07.003

Cao, Y., Wu, Y.-F., and Jiang, C. (2018). Stress-strain relationship of FRP confined concrete columns under combined axial load and bending moment. Compos. $B$ Eng. 134, 207-217.

Casuccio, M., Torrijos, M., Giaccio, G., and Zerbino, R. (2008). Failure mechanism of recycled aggregate concrete. Construct. Build. Mater. 22(7), 1500-1506.

Chen, G. M., He, Y. H., Jiang, T., and Lin, C. J. (2016). Behavior of CFRP-confined recycled aggregate concrete under axial compression. Construct. Build. Mater. 111, 85-97. doi:10.1016/j.conbuildmat.2016.01.054

Chen, X. D., Shi, D. D., Shen, N., Li, S. T., and Liu, S. S. (2019). Experimental Study and Analytical Modeling on Fatigue Properties of Pervious Concrete Made with Natural and Recycled Aggregates. Int. J. Concr. Struct. Mater. 13 (1). doi:10. 1186/s40069-018-0305-0

Dai, J.-G., Bai, Y.-L., and Teng, J. (2011). Behavior and modeling of concrete confined with FRP composites of large deformability. J. Compos. Construct. 15(6), 963-973.

\section{FUNDING}

The work described in this paper was financially supported by the National Natural Science Foundation of China (Grants No. 51808348), Guangdong Basic and Applied Basic Research Fund Project (Grant No. 2020A1515011552), and the Shenzhen Basic Research Project (Grant No. JCYJ20170817100253542), for which the authors are grateful.

\section{ACKNOWLEDGMENTS}

The author also would like to thank Yao Wei, who performed tests reported in this paper as part of his undergraduate thesis.

De Lorenzis, L., and Tepfers, R. (2003). Comparative study of models on confinement of concrete cylinders with fiber-reinforced polymer composites. J. Compos. Construct. 7(3), 219-237. doi:10.1061/(asce)1090-0268(2003)7:3(219)

Etxeberria, M., Vázquez, E., Marí, A., and Barra, M. (2007). Influence of amount of recycled coarse aggregates and production process on properties of recycled aggregate concrete. Cement Concr. Res. 37(5), 735-742. doi:10.1016/j. cemconres.2007.02.002

Girgin, Z. C., and Girgin, K. (2015). A design-oriented combined model (7 MPa to $190 \mathrm{MPa}$ ) for FRP-confined circular short columns. Polymers 7(10), 1905-1917. doi:10.3390/polym7101489

Huang, Y., Xiao, J., and Zhang, C. (2012). Theoretical study on mechanical behavior of steel confined recycled aggregate concrete. J. Constr. Steel Res. 76, 100-111. doi:10.1016/j.jcsr.2012.03.020

Jiang, C., Wu, Y. F., and Jiang, J. F. (2017a). Effect of aggregate size on stress-strain behavior of concrete confined by fiber composites. Compos. Struct. 168, 851-862. doi:10.1016/j.compstruct.2017.02.087

Jiang, J.-f., Xiao, P.-c., and Li, B.-b. (2017b). True-triaxial compressive behaviour of concrete under passive confinement. Construct. Build. Mater. 156, 584-598. doi:10.1016/j.conbuildmat.2017.08.143

Jiang, J. F., and Wu, Y. F. (2012). Identification of material parameters for DruckerPrager plasticity model for FRP confined circular concrete columns. Int. J. Solids Struct. 49 (3-4), 445-456. doi:10.1016/j.ijsolstr.2011.10.002

Jiang, J. F., Wu, Y. F. J. M., and Structures (2016). Plasticity-based criterion for confinement design of FRP jacketed concrete columns. Mater. Struct. 49(6), 2035-2051. doi:10.1617/s11527-015-0632-4

Jiang, T., and Teng, J. G. (2007). Analysis-oriented stress-strain models for FRP-confined concrete. Eng. Struct. 29(11), 2968-2986. doi:10.1016/j.engstruct.2007.01.010

Jishou, Y., Xiaoping, C., Yong, G., and Yening, Y. (2015). Effect of elongated and flaky particles content on the durability of concrete.

Juan, M. S. d., Gutierrez, P. A. J. C., and Materials, B. (2009). Study on the influence of attached mortar content on the properties of recycled concrete aggregate. Construct. Build. Mater. 23(2), p.872-877. doi:10.1016/j.conbuildmat.2008.04.012

Kong, D., Lei, T., Zheng, J., Ma, C., Jiang, J., and Jiang, J. (2010). Effect and mechanism of surface-coating pozzalanics materials around aggregate on properties and ITZ microstructure of recycled aggregate concrete. Construct. Build. Mater. 24(5), 701-708. doi:10.1016/j.conbuildmat.2009.10.038

Kou, S.-C., Zhan, B.-j., and Poon, C.-S. (2014). Use of a CO2 curing step to improve the properties of concrete prepared with recycled aggregates. Cement Concr. Compos. 45, 22-28.

Lam, L., and Teng, J. G. (2003). Design-oriented stress -strain model for FRP confined concrete. Constr. Build. Mater. 17 (6), 471-489. doi:10.1016/S09500618(03)00045-X

Lechat, C., Bunsell, A. R., and Davies, P. (2011). Tensile and creep behaviour of polyethylene terephthalate and polyethylene naphthalate fibres. J. Mater. Sci. 46(2), 528-533. doi:10.1007/s10853-010-4999-x

Li, P., Sui, L., Xing, F., Huang, X., Zhou, Y., and Yun, Y. (2018a). Effects of aggregate types on the stress-strain behavior of fiber reinforced polymer (FRP)confined lightweight concrete. Sensors 18 (10), 3525. doi:10.3390/s18103525 
Li, P., Sui, L., Xing, F., Li, M., Zhou, Y., and Wu, Y.-F. (2019a). Stress-strain relation of FRP-confined predamaged concrete prisms with square sections of different corner radii subjected to monotonic axial compression. J. Compos. Construct. 23(2), 04019001. doi:10.1061/\%28ASCE\%29CC.1943-5614.0000921

Li, P., Sui, L., Xing, F., and Zhou, Y. (2019b). Static and cyclic response of low-strength recycled aggregate concrete strengthened using fiberreinforced polymer. Compos. B Eng. 160, 37-49. doi:10.1016/j. compositesb.2018.10.002

Li, P., Wu, Y.-F., Zhou, Y., and Xing, F. (2018). Cyclic stress-strain model for FRPconfined concrete considering post-peak softening. Compos. Struct. 201, 902-915. doi:10.1016/j.compstruct.2018.06.088

Li, P., and Wu, Y. F. (2016). Stress-strain behavior of actively and passively confined concrete under cyclic axial load. Compos. Struct. 149, 369-384. doi:10. 1016/j.compstruct.2016.04.033

Mohammadi, M., and Wu, Y.-F. (2017). Triaxial test for concrete under nonuniform passive confinement. Construct. Build. Mater. 138, 455-468. doi:10. 1016/j.conbuildmat.2017.02.032

Molugaram, K., Shanker, J. S., and Ramesh, A. (2014). A study on influence of shape of aggregate on strength and quality of concrete for buildings and pavements. Adv. Mater. Res. 941-944, 776-779. doi:10.4028/www.scientific. net/AMR.

Nisticò, N., and Monti, G. (2013). RC square sections confined by FRP: Analytical prediction of peak strength. Composites 45 (1), 127-137. doi:10.1016/j. compositesb.2012.09.041

Omary, S., Ghorbel, E., and Wardeh, G. (2016). Relationships between recycled concrete aggregates characteristics and recycled aggregates concretes properties. Construct. Build. Mater. 108, 163-174. doi:10.1016/j.conbuildmat. 2016.01.042

Ponnada, M. R. (2014). Combined effect of flaky and elongated aggregates on strength and workability of concrete. Struct. Eng. Int. 5(4), 314-325.

Poon, C. S., Shui, Z. H., and Lam, L. (2004). Effect of microstructure of ITZ on compressive strength of concrete prepared with recycled aggregates. Construct. Build. Mater. 18(6), 461-468. doi:10.1016/j.conbuildmat.2004.03.005

Rousakis, T. C. (2018). Inherent seismic resilience of RC columns externally confined with nonbonded composite ropes. Composites 135, 142-148. doi:10.1016/j.compositesb.2017.10.023

Shi, C., Li, Y., Zhang, J., Li, W., Chong, L., and Xie, Z. (2016). Performance enhancement of recycled concrete aggregate-a review. J. Clean. Prod. 112, 466-472. doi:10.1016/j.jclepro.2015.08.057

Silva, R. V., de Brito, J., and Dhir, R. K. (2014). Properties and composition of recycled aggregates from construction and demolition waste suitable for concrete production. Construct. Build. Mater. 65, 201-217. doi:10.1016/j. conbuildmat.2014.04.117

Song, X. B., Gu, X. L., Li, Y. P., Chen, T., and Zhang, W. P. (2013). Mechanical Behavior of FRP-Strengthened Concrete Columns Subjected to Concentric and Eccentric Compression Loading. J. Compos. Constr. 17 (3), 336-346. doi:10. 1061/(asce)cc.1943-5614.0000351

Tabsh, S. W., and Abdelfatah, A. S. (2009). Influence of recycled concrete aggregates on strength properties of concrete. Construct. Build. Mater. 23(2), 1163-1167. doi:10.1016/j.conbuildmat.2008.06.007

Wei, Y., Zhang, Y., Chai, J., Wu, G., and Dong, Z. (2020). Experimental investigation of rectangular concrete-filled fiber reinforced polymer (FRP)steel composite tube columns for various corner radii. Composite Structures, 244, 112311. doi:10.1016/j.compstruct.2020.112311
Wu, Y.-F., Yun, Y., Wei, Y., and Zhou, Y. (2014). Effect of predamage on the stressstrain relationship of confined concrete under monotonic loading. Struct. Eng. 140(12), 04014093. doi:10.1061/(ASCE)ST.1943-541X.0001015

Wu, Y. F., and Cao, Y. G. (2017). Effect of load path on behavior of FRP-confined concrete. J. Compos. Construct. 21(4), 04017014. doi:10.1061/(ASCE)CC.19435614.0000799

Xianglin, G., Tran, Y., and Li, H. (2014). Quantification of coarse aggregate shape in concrete. Front. Struct. Civ. Eng. 8(3), 308-321. doi:10.1007/s11709-0140266-6

Xiao, J., Li, L., Shen, L., and Poon, C. S. (2015). Compressive behaviour of recycled aggregate concrete under impact loading. Cement Concr. Res. 71, 46-55. doi:10. 1016/j.cemconres.2015.01.014

Xiao, J. (2018). "Recycled aggregate concrete," in Recycled aggregate concrete structures. (Springer), 65-98.

Xiao, J. Z., Li, J. B., and Zhang, C. (2005). Mechanical properties of recycled aggregate concrete under uniaxial loading. Cement Concr. Res. 35(6), 1187-1194. doi:10.1016/j.cemconres.2004.09.020

Xiao, J. Z., Li, W. G., Fan, Y. H., and Huang, X. (2012). An overview of study on recycled aggregate concrete in China (1996-2011). Construct. Build. Mater. 31, 364-383. doi:10.1016/j.conbuildmat.2011.12.074

Zeng, J., Lin, G., Teng, J., and Li, L. (2018). Behavior of large-scale FRPconfined rectangular RC columns under axial compression. Eng. Struct. 174, 629-645. doi:10.1016/j.engstruct.2018.07.086

Zhang, Y. R., Luo, W., Wang, J. J., Wang, Y. F., Xu, Y. Q., and Xiao, J. Z. (2019). A review of life cycle assessment of recycled aggregate concrete. Construct. Build. Mater. 209, 115-125. doi:10.1016/j.conbuildmat.2019.03.078

Zhang, Z. Q., Zhang, Y. F., Yan, C. G., and Liu, Y. X. (2017). Influence of crushing index on properties of recycled aggregates pervious concrete. Construct. Build. Mater. 135, 112-118. doi:10.1016/j.conbuildmat.2016.12.203

Zhao, J. L., Yu, T., and Teng, J. G. (2015). Stress-strain behavior of FRP-confined recycled aggregate concrete. J. Compos. Construct. 19(3). doi:10.1061/(asce)cc. 1943-5614.0000513

Zhou, J. H., He, H. J., Meng, X. H., and Huan, S. (2010). Experimental study of recycled concrete columns under large eccentric compression. Earth and space 531-538. doi:10.1061/41096\%28366\%2954

Zhou, Y., Hu, J., Li, M., Sui, L., and Xing, F. (2016). FRP-confined recycled coarse aggregate concrete: experimental investigation and model comparison. Polymers 8(10). doi:10.3390/polym8100375

Zhou, Y., Zheng, Y., Pan, J., Sui, L., Xing, F., and Sun, H., et al. (2019). Experimental investigations on corrosion resistance of innovative steel-FRP composite bars using X-ray microcomputed tomography. Composites 161, 272-284. doi:10. 1016/j.compositesb.2018.10.069

Conflict of Interest: The authors declare that the research was conducted in the absence of any commercial or financial relationships that could be construed as a potential conflict of interest.

Copyright (c) $2020 \mathrm{Li}$, Zhao, Long, Zhou and Chen. This is an open-access article distributed under the terms of the Creative Commons Attribution License (CC BY). The use, distribution or reproduction in other forums is permitted, provided the original author(s) and the copyright owner(s) are credited and that the original publication in this journal is cited, in accordance with accepted academic practice. No use, distribution or reproduction is permitted which does not comply with these terms. 